\title{
Joy e as Letrinhas: um Serious Game como ferramenta de auxílio no processo de alfabetização de crianças do ensino fundamental
}

\author{
Title: Joy e as Letrinhas: a Serious Game as aid tool in the process of education of children \\ of literacy fundamental
}

Mateus José de Faria

Faculdade de Tecnologia de Mococa - FATEC

mateus034@hotmail.com

\author{
Rogério Colpani \\ Faculdade de Tecnologia de Mococa - FATEC \\ rocolpani@gmail.com
}

\begin{abstract}
Resumo
Os métodos tradicionais de ensino, focados no educador, giz e quadro negro, cada vez mais dão lugar às inovações $e$ às novas tecnologias, como os jogos eletrônicos educativos. Com este intuito, o presente artigo propõe o desenvolvimento de um Serious Game, batizado de "Joy e as Letrinhas", com proposito de auxiliar professores no processo de ensino/aprendizagem da alfabetização de crianças em início escolar. De forma a avaliar da melhor maneira a qualidade do Serious Game, o mesmo passou por avaliações seguindo os métodos quantitativos e qualitativos. Na etapa quantitativa, foram mensuradas as habilidades das crianças, utilizadas no estudo, antes e após a utilização do Serious Game, assim como a análise estatística, teste $t$, e a estatística descritiva de modo a organizar resumir e exibir os resultados alcançados. Na etapa qualitativa, foram avaliadas, por intermédio de pedagogas, as usabilidades técnicas e pedagógicas a fim de se ter opiniões quanto à facilidade de aprendizagem e de utilização. Os resultados obtidos permitem apontar que o Serious Game "Joy e as letrinhas" contribui para a evolução das habilidades das crianças, proporcionando um aprendizado lúdico, divertido, despertando o interesse, interação e realização das atividades.
\end{abstract}

Palavras-Chave: Aprendizagem, Alfabetização, Serious Game.

\begin{abstract}
Traditional teaching methods, focused on educator, chalkboard and blackboard, increasingly give way to innovations and new technologies, such as educational electronic games. With this purpose, the present article proposes the development of a Serious Game, called "Joy e as Letrinhas", with the purpose of assisting teachers in the process of teaching / learning the literacy of children at school. In order to better evaluate the quality of the Serious Game, it has undergone evaluations following quantitative and qualitative methods. In the quantitative stage, the children's abilities, used in the study, were measured before and after the use of the Serious Game, as well as the statistical analysis, $t$ test, and the descriptive statistics in order to organize summarize and display the results achieved. In the qualitative stage, the pedagogical and technical usages were evaluated through pedagogues in order to have opinions about the ease of learning and use. The results obtained allow us to point out that Serious Game "Joy e as Letrinhas" contribute to the evolution of the children's abilities, providing a playful, fun learning, arousing the interest, interaction and accomplishment of the activities.
\end{abstract}

Keywords: Learning, Literacy, Serious Game.

Faria, M. J. \& Colpani, R. (2017). Joy e as Letrinhas: a Serious Game as aid tool in the process of education of children of literacy fundamental (Joy e as Letrinhas: um Serious Game como ferramenta de auxílio no processo de alfabetização de crianças do ensino fundamental). Brazilian Journal of Computers in Education (Revista Brasileira de Informática na Educação - RBIE), 25(2), 61-86. DOI: 10.5753/RBIE.2017.25.02.63 


\section{Introdução}

A alfabetização das crianças, nos primeiros anos do ensino fundamental, é de suma importância, visto que esta etapa estabelece o ponto de partida para o ensino formal da leitura/escrita. Neste ponto, qualquer equívoco poderá provocar consequências que podem acompanhar a criança por toda a vida (Martin, 2005).

O ensino fundamental enfrenta alguns dos principais desafios para os próximos anos, cerca de 15,2\% das crianças, segundo Censo/IBGE em 2010, não foram alfabetizadas até os oito anos de idade. Visando à alfabetização das crianças até os oito anos, a Avaliação Brasileira do Ciclo de Alfabetização, Prova ABC, indica que em 2011, cerca de 51,4\% das crianças não alcançaram os níveis de conhecimento esperados. Já os dados evidenciados pelo De Olho Nas Metas 2012, por intermédio da Prova ABC, apenas 39,7\% das crianças até o $3^{\circ}$ ano alcançaram os níveis ideais de aprendizagem em leitura e 25,9\% em escrita (Cruz \& Monteiro, 2012; Todos Pela Educação, 2013).

Alguns dos principais problemas e dificuldades enfrentados na educação são decorrentes de fatores orgânicos, psicológicos, pedagógicos e socioculturais. Tais dificuldades podem causar instabilidade emocional, dificuldade em manter a atenção, inquietude, problemas de comunicação, indisciplina, desmotivação, baixo rendimento, desobediência e mal comportamento (Bartholomeu, Sisto \& Rueda, 2006; Domingos, 2007; Silva, Couto \& França, 2013).

Diante de tantas barreiras, o professor vem enfrentando duros desafios para alcançar com êxito o processo de alfabetização. A educação brasileira passou por grandes mudanças, o aluno deixou de ser mero ouvinte passando a ser o protagonista no processo de ensino/aprendizagem. Nesta circunstância, o professor cada vez mais necessita de ferramentas que estimulem e despertem no aluno o interesse na busca da construção do conhecimento e minimize as dificuldades que abalam o seu aprendizado (Silva, Couto \& França, 2013).

Neste contexto, uma das ferramentas que podem minimizar boa parte das dificuldades e motivar as crianças são os Serious Games. Os Serious Games são recursos didáticos que têm se destacado nos últimos anos, enriquecendo as aulas, fazendo-as dinâmicas e motivadoras, contribuindo para a qualidade do ensino e reforçando conceitos (Karlini \& Rigo, 2014).

Segundo Machado, Moraes, Nunes e Costa (2011), podemos definir Serious Games como uma classe de jogos, cujo objetivo principal é simular situações práticas, proporcionar treinamentos, auxiliar tomadas de decisão, conscientizar crianças, jovens e adultos e a educação em temas específicos. Estes jogos oferecem atividades que ajudam na construção de conceitos e a estimulação das funções psicomotoras.

A utilização dos Serious Games aproximam os alunos dos conteúdos a serem ministrados, facilitando não apenas a absorção do conhecimento, mas oferecendo a oportunidade para que todos possam aprender, transpondo barreiras que possam vir a dificultar a aprendizagem. Segundo Savi e Ulbricht (2008), muitos são os benefícios que podem ser observados no emprego dos Serious Games na educação, tais como:

Efeito motivador: capacidade de divertir e entreter o usuário e, ao mesmo tempo, o incentiva a aprender por meio da interação e dinamismo, despertando a curiosidade, a fantasia, sentimento de aventura e prazer.

Facilitador do aprendizado: capacidade de favorecer o aprendizado contribuindo para o desenvolvimento de diversas áreas como a resolução de problemas, raciocínio lógico, dedutivo, memorização, habilidades psicomotoras e analíticas. 
Desenvolvimento de habilidades cognitivas: os Serious Games favorecem o desenvolvimento intelectual, pois para vencer os desafios, a criança necessita elaborar certas estratégias e compreender como os diferentes elementos do jogo se relacionam.

Em sala de aula, os jogos podem promover o aprendizado mais rapidamente e com eficácia ainda maior perante os métodos tradicionais, uma vez que eles permitem que a criança possa repetir diversas vezes a mesma etapa até aprender o que lhe foi proposto. Além disso, os Serious Games oferecem às crianças um maior controle sobre sua própria aprendizagem, aumentando sua autoestima, entusiasmo e engajamento. Outra vantagem que deve ser destacada é a abordagem de mais de um tema, inserindo as crianças em temáticas importantes a sua formação como cidadãos (Fleury, Nakano \& Cordeiro, 2014).

Com base no exposto, esta pesquisa tem como objetivo apresentar o Serious Game "Joy e as Letrinhas" para auxílio no processo de ensino/aprendizagem da alfabetização de crianças em início escolar.

O artigo está estruturado em seis seções. Na primeira seção, é feita uma introdução ao tema, expondo a problemática em números e como estes problemas e dificuldades podem ser minimizados. A segunda seção apresenta uma breve contextualização sobre alfabetização, jogos na educação, os principais conceitos sobre Serious Games na educação e trabalhos correlatos. A terceira seção abordará os procedimentos metodológicos e ferramentas utilizadas no desenvolvimento do Serious Game e descrição das atividades durante a utilização do mesmo. A quarta seção abordará o protocolo de avaliação do Serious Game com participantes dos projetos do Artesanato - Centro de Desenvolvimento Social de Mococa, situado na cidade de MococaSP. Na quinta seção serão apresentados os resultados quantitativos e qualitativos da pesquisa em questão. Por fim, a sexta seção apresenta a conclusão do trabalho e trabalhos futuros.

\section{Fundamentação Teórica}

\subsection{Alfabetização}

Segundo Soares (1998), o significado de alfabetização é a ação de alfabetizar, ensinar o indivíduo a interpretar e reproduzir os símbolos da escrita. Moreira e Rocha (2013) afirmam que a alfabetização pode ser entendida como a aquisição do sistema alfabético de escrita ou como o processo pelo qual o indivíduo torna-se capaz de ler, compreender o texto e se expressar por escrito. Lazarotto (2010) relata que alfabetizar é condicionar ao indivíduo a capacidade de ler e escrever. A alfabetização não é um processo ao qual se chega, mas um procedimento cujo início é anterior à escola e que não termina ao finalizar o primário.

Do ponto de vista pedagógico, a alfabetização desempenha um papel concreto, assegurando às crianças uma aprendizagem de novas formas de expressão. Assim, juntamente com a valorização da sua realidade e conhecimentos prévios, as técnicas de leitura e escrita são beneficiadas e o desempenho aumentado (Silva \& Rodrigues, 2011).

Segundo Araújo (2002), o desempenho das crianças nas instituições de ensino dependem claramente de diferentes fatores, como característica escolar, familiar, social e do próprio indivíduo, que podem caracterizar ou não dificuldades e deficiências de aprendizagem.

O aprendizado é um grande desafio, o que não indica deficiência na aprendizagem, mas que todas as crianças têm seus pontos fortes e fracos tratando-se da aprendizagem. Alguns aprendem melhor ouvindo e outros visualizando. Entretanto, as crianças ficam misturadas em uma sala, as quais são submetidas ao mesmo método de ensino, trazendo assim para algumas crianças, problemas e dificuldades de aprendizagem (Domingos, 2007; Petronilo, 2007). 
De acordo com Domingos (2007), as maiores dificuldades encontradas são:

- Dificuldade global: envolve aspectos sociais, culturais e emocionais. Como exemplo, pode-se citar a didática empregada, problemas no âmbito familiar, choque regional, uso de medicamentos ou drogas ou deficiências auditivas e visuais.

- Imaturidade funcional: dificuldades cerebrais limitadas, que podem melhorar após o tratamento, podem ser causadas por disfunções ou causas emocionais.

- Disfunção cerebral: estas disfunções afetam áreas relacionadas a linguagem, leitura, escrita, cálculo e etc.

Os problemas supracitados evidenciam a problemática em que o país se encontra. $\mathrm{O}$ Brasil criou diversas ferramentas para mensurar a qualidade do ensino. Dentre estas ferramentas, destaca-se a ANA (Avaliação Nacional de Alfabetização) que em 2015 divulgou os dados mensurados no ano anterior, onde $22,21 \%$ das crianças não alcançaram os níveis necessários de proficiência em leitura e 34,46\% em escrita (Ministério da Educação, 2015).

Segundo Pereira, Vitória, Santos e Machado (2013), outro ponto que deve ser observado na alfabetização são os métodos utilizados. Com a necessidade de alfabetizar, surgiram os métodos de ensino, nos quais são impostos regras que devem ser seguidas pelas crianças. Estes métodos devem ter uma atenção especial para que possam ser uma chave para tentar diminuir as lacunas existentes na educação brasileira e não o contrário.

Segundo Nascimento e Cavalcante (2012), o maior desafio para os professores é a identificação de métodos construtivistas para o processo de aprendizagem. Estes métodos devem garantir a ludicidade da educação e contribuir com o desenvolvimento da criança em todos os aspectos.

\subsection{Serious Games na educação}

A definição de Serious Games são jogos cuja função não se propaga apenas pelo entretenimento, mas também como meio criador de atitudes, um instrumento educativo e/ou de treinamento. Desta forma, os Serious Games se caracterizam como jogos que possuem atributos mecânicos e funcionais de vídeo games, mas têm como propósito principal o aprendizado (Vanni, 2014).

Os Serious Games têm como característica principal a criação de ambientes fundamentados no desenvolvimento de competências como a criatividade, memória e a cooperatividade. Diferente dos métodos de ensino comuns, os Serious Games incorporam o jogador a um ambiente lúdico, possibilitando a propagação de conhecimentos com eficiência. Além de educar, os Serious Games incorporam o jogador a situações reais, simplificando a adaptação do conteúdo aprendido no jogo à realidade. A resolução de problemas complexos, seguida de feedback, tornam os jogadores mais familiarizados a encarar obstáculos frequentes, além de ensiná-los que falhar também é comum e que falhas podem ser contornadas (Klopfer, Osterweil \& Salen, 2009).

Ao agregar cores, sons e movimentos às palavras, letras e sílabas, o jogo começa a fazer sentido ao jogador, sentido que, em muitos casos, nem mesmo os livros ou materiais didáticos conseguem lhe dar. Assim, espera-se que a alfabetização, com a ajuda dos Serious Games, rompa o tradicionalismo, fixando-se como elemento fundamental para a educação (Araújo \& Rodrigues, 2007).

Alguns Serious Games disponibilizam aos jogadores a alternativa de realizar atividades ou tarefas em grupos. Com estas características, contribuem para o treinamento de atividades colaborativas, utilizando redes de comunicação para a interação dos jogadores. Esta cooperação possibilita aos jogadores a troca de experiências e a contribuição do aprendizado de forma conjunta (Costa, Machado \& Morais, 2014). 
Rocha (2015) enumera três motivos pelos quais os Serious Games satisfazem a aprendizagem. O primeiro, denominado "envolvimento", ocorre em função da aprendizagem estar relacionada à dinâmica do jogo, estimulando e motivando aqueles que são avessos ao aprendizado. Em seguida, destaca-se o processo interativo de aprendizagem, que apresenta muitas maneiras de se jogar de acordo com os objetivos da aprendizagem, estimulando a participação e cooperação dos alunos. Por fim, o modo como o ensino e os jogos complementam-se, promovendo maneiras diferentes de serem empregados.

Como trabalhos correlatos, Barboza e Silveira (2015) apresentam uma proposta de um Serious Game destinado ao ensino do alfabeto a crianças em início escolar. O referido trabalho tem como objetivo promover o contato da criança com o alfabeto através do formato das letras e de seus sons, assim como, as palavras e os sons formados por elas. Este jogo é formado por dois mini jogos e uma área com cartas que apresentam a escrita das letras, palavras e imagens associadas a elas. Este Serious Game espera como resultado motivar as crianças, por meio do jogo, a aprender o alfabeto e as palavras formadas por ele de uma maneira lúdica.

Posteriormente, o projeto Letramento em Ambientes Digitais Multimodais - ALADIM, de Coscarelli, Gonçalves, Dallapicula e Mota (2008), tem como objetivo desenvolver jogos de plataforma voltados para a alfabetização. Um dos jogos desenvolvidos é o Papa Letras, uma roupagem do jogo PAC-MAN. O jogo acontece da mesma forma que em PAC-MAN, em um labirinto, onde monstros perseguem o personagem principal e o mesmo deve desviar-se para não ser atingido. $\mathrm{O}$ diferencial do jogo são as sílabas espalhadas pelo labirinto, onde o personagem deve coletá-las para formar a palavra da imagem apresentada no centro da tela. O jogo proporciona ao jogador a oportunidade de testar seus conhecimentos de modo a tornar-se um complemento à alfabetização escolar, visto que, desenvolve a compreensão de imagens e a utilização de elementos gráficos utilizados para sua representação.

Karlini e Rigo (2014) desenvolveram o ABCLingo, composto por atividades de cunho alfabético, onde cada nível corresponde a uma vogal. O objetivo deste jogo é fazer com que a criança complete as atividades, por níveis distintos, recuperando os respectivos objetos, os quais serão utilizados para abrir uma porta mágica no fim do jogo. Este protótipo é voltado ao letramento e armazena alguns dados relevantes que podem ser utilizados em uma ferramenta de mineração de dados para que possam ser feitas análises por profissionais da área pedagógica.

Por fim, Gulo et. al. (2011) apresentam o jogo GCompris, o qual faz parte do software Pandorga GNU/Linux. Este software educativo é gratuito e possui diversas atividades voltadas para a alfabetização, além de ser planejado para que suas atividades sejam de fácil manipulação. As atividades variam e, por exemplo, proporcionam ao aluno habilidade de reconhecimento do posicionamento das letras do teclado promovendo a melhora da coordenação na digitação de palavras. O jogo oferece relatórios das atividades e a possibilidade de acompanhar os resultados de um aluno em especial ou todos os alunos. A utilização deste jogo mostrou-se aplicável por adequar-se aos conteúdos exigidos e como reforço ao conteúdo específico para os alunos.

Com base nos trabalhos correlatos supracitados e o Serious Game da presente pesquisa, é possível identificar alguns pontos de convergência. Os trabalhos destacam a importância da alfabetização e os meios para que a mesma seja ensinada de forma lúdica, despertando o interesse da criança e contornando certas dificuldades que os métodos de ensino tradicionais podem não circundar.

Para tornar estes Serious Games atrativos às crianças, os mesmos são dotados de uma combinação de imagens coloridas, sons e músicas, o que pode promover a diversão e o aprendizado. Segundo Rivas, Silva e Conte (2014), os recursos audiovisuais são essenciais para a aprendizagem, uma vez que estas mídias ajudam o aluno na percepção e retenção de informações transmitidas pelos jogos. 
Com base na análise dos artigos correlatos, os mesmos não apresentam protocolos de avaliação com coletas de dados, métodos de análise, pesquisas qualitativas, quantitativas e análise de resultados. Baseando-se nos resultados obtidos na pesquisa qualitativa e quantitativa da presente pesquisa, é possível observar que este Serious Game contribui para processo de ensino/aprendizagem, minimizando os problemas de aprendizagem apresentados pelas crianças em comparação aos métodos de ensino tradicionais.

Como pontos de divergência, vale ressaltar que o Serious Game da presente pesquisa não possui ferramentas de monitoramento, cabendo ao professor diagnosticar as possíveis deficiências contidas no grupo de crianças que estiverem jogando. Neste aspecto, o professor deverá buscar os métodos mais adequados para a correção dos problemas de aprendizagem encontrados.

\section{Joy e as Letrinhas}

\subsection{Metodologia de desenvolvimento}

Ao dar início à criação de um Serious Game pedagógico, duas pedagogas, que trabalham na instituição em que foi feito o estudo, foram consultadas sobre as pretensões do software, a viabilidade do seu desenvolvimento e o levantamento das necessidades que definiriam as suas características. Logo após, foi iniciado o planejamento e o levantamento de requisitos, levando em conta o emprego dos conteúdos didáticos de forma lúdica e os resultados esperados.

O modelo de desenvolvimento mais apropriado para a utilização foi o Modelo Evolucionário. Os modelos evolucionários produzem versões de softwares cada vez mais completas a cada iteração. Estes modelos de processos identificam o cunho interativo da maior parte dos projetos de engenharia de software e são planejados para acomodar as modificações necessárias até que se chegue a um sistema que atenda às necessidades dos clientes (Oliveira, 2013).

Modelos deste tipo podem ser aplicados no decorrer de todas as atividades da engenharia de software, apresentando um grande potencial para o desenvolvimento rápido por meio de protótipos. Este método facilita a interação e compreensão do software por desenvolvedores e clientes, quando os requisitos não são claros, além de permitir uma prévia do software para a avaliação (Oliveira, 2013).

A escolha deste modelo foi devido à rapidez de desenvolvimento e à capacidade de concepção de protótipos para a avaliação. Estes elementos elevaram a qualidade do software, além de aumentar o refinamento do mesmo, tornando o projeto ágil, versátil e adaptado a mudanças inesperadas.

\subsection{Especificação dos requisitos}

O levantamento de requisitos foi realizado em uma instituição filantrópica assistencial da cidade de Mococa-SP, chamada Artesanato - Centro de Desenvolvimento Social de Mococa. Esta instituição atende crianças e adolescentes de 6 à 17 anos e 11 meses, oferecendo-lhes oficinas culturais e alimentação, além de assistência psicológica e social.

O levantamento foi elaborado por meio de entrevistas com as pedagogas participantes do projeto, conforme o modelo utilizado, feito in loco e em várias etapas, conduzindo assim todo o processo de desenvolvimento. As crianças utilizadas nos testes têm entre 6 à 8 anos de idade, entre meninos e meninas que frequentam ativamente a escola normal da própria cidade. 
Para o referido levantamento, foram levados em consideração a idade do público alvo, seu nível de aprendizado alfabético, o conteúdo programático exigido pelo Ministério da Educação e os anos de experiência e prática das pedagogas. Estes fatores são de suma importância para que o aprendizado se manifeste de maneira semelhante ou superior aos métodos tradicionais.

O levantamento de requisitos foi dividido em duas partes, sendo os requisitos funcionais, apresentados Quadro 1, e os requisitos não funcionais, apresentados no Quadro 2.

Quadro 1: Requisitos funcionais.

\begin{tabular}{|c|l|}
\hline \multicolumn{2}{|c|}{ Requisitos Funcionais } \\
\hline 01 & $\begin{array}{l}\text { Possibilidade de ordenação da sequência das vogais de maneira aleatória entre as } \\
\text { consoantes. }\end{array}$ \\
\hline 02 & $\begin{array}{l}\text { Possibilidade de ordenação da sequência das consoantes de maneira aleatória } \\
\text { entre as vogais. }\end{array}$ \\
\hline 03 & $\begin{array}{l}\text { Possibilidade de ordenação da sequência das vogais de maneira aleatória sem a } \\
\text { presença de consoantes. }\end{array}$ \\
\hline 04 & Coleta de vogais e consoantes de forma a possibilitar a distinção dos fonemas. \\
\hline 05 & $\begin{array}{l}\text { Possibilidade da identificação da palavra e letras utilizadas por meio de áudio e } \\
\text { contexto gráfico. }\end{array}$ \\
\hline 06 & Apoio de palavras de cunho conhecido para o complemento da mesma. \\
\hline 07 & $\begin{array}{l}\text { Possibilidade da identificação da palavra e sílabas utilizadas por meio de áudio e } \\
\text { contexto gráfico. }\end{array}$ \\
\hline
\end{tabular}

Quadro 2: Requisitos não funcionais.

\begin{tabular}{|l|l|}
\hline \multicolumn{2}{|c|}{ Requisitos Não Funcionais } \\
\hline 01 & Possuir botões de fácil localização. \\
\hline 02 & As letras utilizadas devem ser em caixa alta (maiúsculas). \\
\hline 03 & As imagens representativas devem ser claras. \\
\hline 04 & O software deve demonstrar um exemplo de como as atividades devem ser feitas. \\
\hline 05 & O software deve promover feedback para erros, acertos e término da atividade. \\
\hline 06 & Navegação pelo jogo deve ser intuitiva. \\
\hline 07 & O software deve ser suscetível ao menor número de falhas possível. \\
\hline 08 & O software deve apresentar tempo de resposta rápido. \\
\hline 09 & O software deverá ser desenvolvido para multiplataforma. \\
\hline 10 & O software deverá ser compatível como HTML5. \\
\hline
\end{tabular}

\subsection{Ferramentas de desenvolvimento}

Na criação do Serious Game "Joy e as Letrinhas", foram utilizadas algumas ferramentas de edição e vetorização de imagens, além da engine de desenvolvimento. Como editor, foi utilizado o software Adobe Photoshop $\mathrm{CC}^{1}$, principalmente em correções e redimensionamento de algumas imagens. Para a criação de personagens e alguns cenários, foi utilizado o CorelDraw $X 7^{2}$, ferramenta fundamental para finalização de arte e criação de novos objetos.

A engine utilizada para o desenvolvimento foi o Construct $2^{3}$, que possui um sistema de drag-and-drop e fornece uma série de scripts prontos que facilita sua utilização. Este motor tem como foco a criação de jogos em duas dimensões (2D), sendo dotado de recursos e sistemas de

\footnotetext{
${ }^{1} \mathrm{http}: / /$ www.adobe.com/br/products/photoshop.html

${ }^{2} \mathrm{http}: / / \mathrm{www}$. coreldraw.com/br

${ }^{3}$ https://www.scirra.com
} 
física, de áudio e de gráficos. Com todas estas facilidades, o Construct 2, torna-se uma ferramenta atrativa e de rápido desenvolvimento.

\subsection{Descrição do Serious Game Joy e as Letrinhas}

O Serious Game "Joy e as Letrinhas" tem como personagem principal o "Professor Joy" e sua tutora "Professora Angélica". Conforme o personagem principal se aventura pelas atividades, sua tutora o direciona, explicando passo a passo o que deve ser feito em cada cenário. Os cenários do jogo foram desenvolvidos de forma a explorar a imaginação das crianças, apresentando um mundo divertido e empolgante, com cores alegres e um ambiente dinâmico. Os conteúdos abordados são referentes àqueles oferecidos pelas pedagogas participantes do estudo, seguindo um nível de dificuldade desde a ordenação de vogais até a escrita de palavras por meio de sílabas. Este Serious Game levou em torno de sete meses para ser desenvolvido.

O cenário inicial do jogo, apresentado na Figura 1, contém alguns botões, tais como "Jogar", "Créditos" e "Sair", que levam a diferentes cenários. Esta tela foi desenvolvida com o intuito de prender a atenção das crianças por ser dinâmica, colorida e divertida.

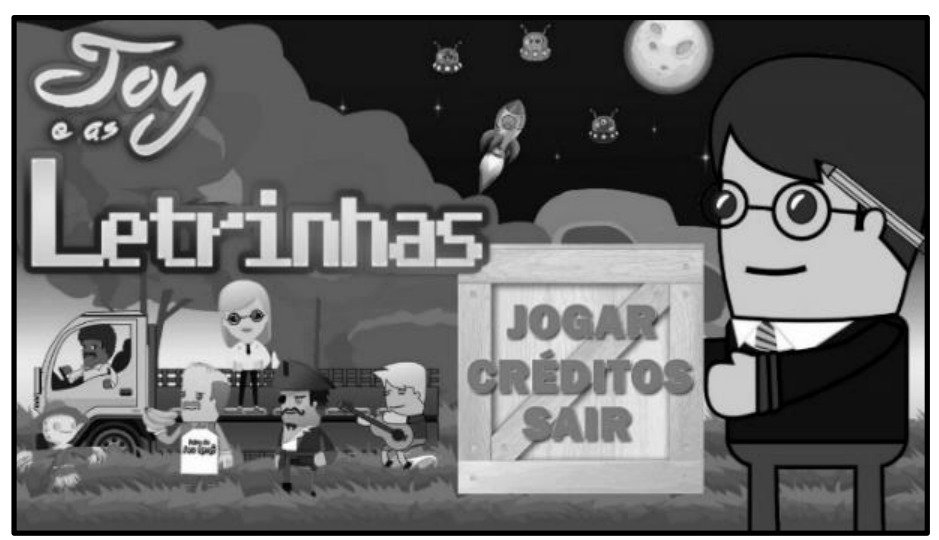

Figura 1: Tela inicial do Serious Game "Joy e as Letrinhas".

O próximo cenário do jogo é a tela de escolha do nome do jogador, apresentado na Figura 2, onde o mesmo poderá escrever seu nome com escolha máxima de dez caracteres. Para auxiliá-lo, existem referências escritas e uma personagem, "Professora Angélica", que descreve em áudio o que deve ser feito pelo jogador.

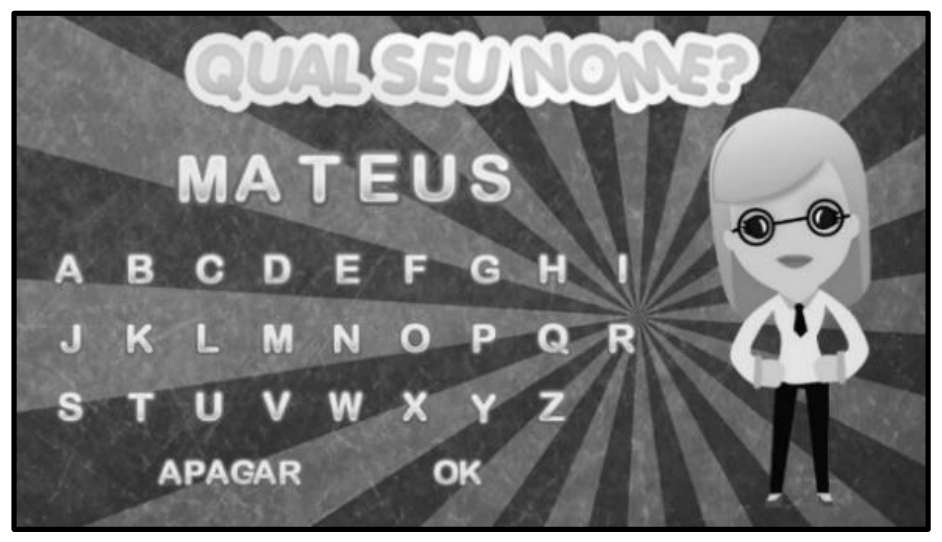

Figura 2: Tela da escolha do nome. 
O cenário posterior é a tela de escolha de fases, apresentado na Figura 3, onde estão dispostas oito fases a serem escolhidas pelo jogador, além de um botão que leva até o cenário de escolha de personagens. Pensando em uma possível dificuldade que alguns jogadores poderiam sentir, o cenário em questão possui botões grandes, permitindo uma área maior para o clique do mouse.

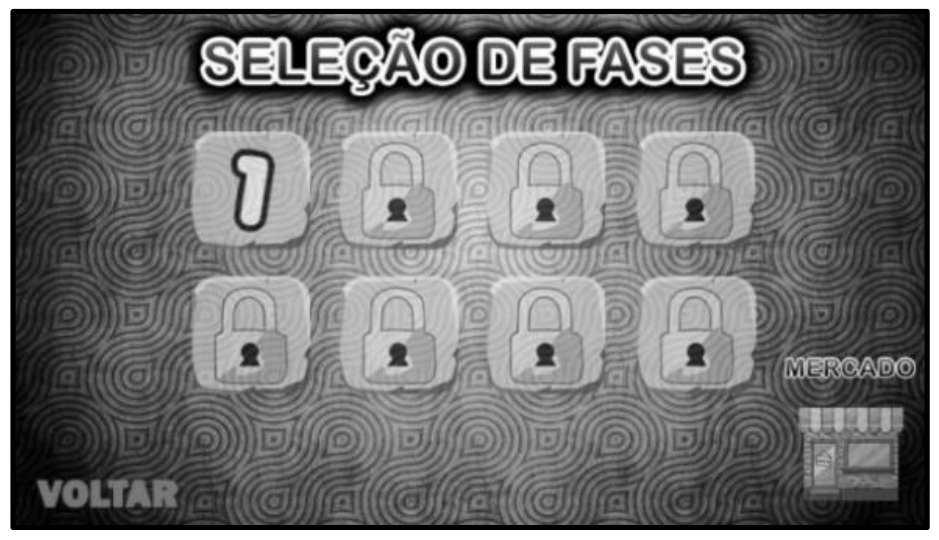

Figura 3: Tela da seleção de fases.

O cenário de escolha de personagens, apresentado na Figura 4, contém cinco personagens selecionáveis, sendo o primeiro padrão. Os personagens foram criados de forma a abordar diferentes perfis com o intuito de chamar a atenção das crianças. Cada um deles apresenta uma característica que o difere dos outros, tornando-os únicos. O personagem padrão, Joy, representa o estilo "estudioso", trazendo consigo características relacionadas a um intelectual. O personagem Billy representa o estilo "lutador", abordando características e virtudes relacionadas a perseverança e persistência. $\mathrm{O}$ personagem $\mathrm{Mr}$. X representa o estilo "investigador", apresentando características relacionadas a inteligência e a astúcia. O personagem Homem Areia representa o estilo "super-herói", abordando características relacionadas a força e ao poder. Por fim, o personagem Eddy representa o estilo "músico", apresentando características e virtudes relacionadas a disciplina e força de vontade. Os personagens em questão foram concebidos de forma criativa e aleatória, buscando diferir os mesmos de personagens famosos.

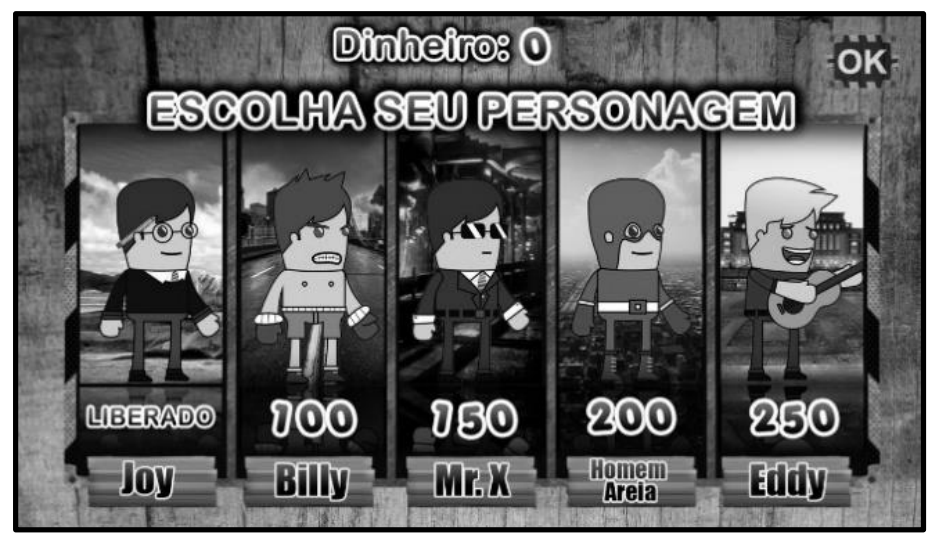

Figura 4: Tela de compra e escolha de personagens.

O próximo cenário, apresentado na Figura 5, é a tela da mini fase "Como Jogar". Este cenário é uma fase/tutorial que ensina os controles básicos do jogo por meio de feedbacks de áudio e imagem, criando meios para que o jogador compreenda o que deve ser feito nas fases seguintes. 


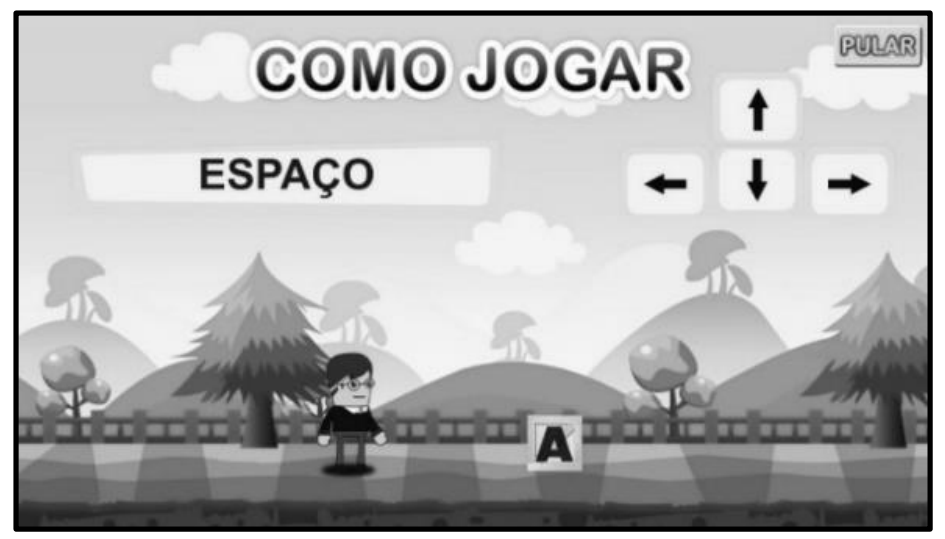

Figura 5: Tela da mini fase "Como Jogar" - Como pegar objetos.

A fase 1, apresentada na Figura 6, é ambientada em uma fábrica, onde o jogador deverá completar o alfabeto utilizando as vogais. Ao iniciar esta fase, como primeiro feedback, a "Professora Angélica" explica em detalhes a atividade e o que o jogador deverá fazer e como fazer. Simultaneamente, aparecerá um quadro na tela que exibirá um pequeno vídeo ensinando exatamente o que deverá ser feito.

Segundo uma das pedagogas participantes do projeto, através desta atividade, é possível que o professor diagnostique crianças que ainda não conhecem as letras do alfabeto e/ou sua sequência, possibilitando assim, direcionar suas atividades de uma forma mais eficiente. Esta atividade é uma forma de aprendizado àqueles que ainda estão em processo de alfabetização, incentivando-os a conhecer as vogais, trabalhando sua ordem. Além disso, auxilia a criança a identificar vogais por traço e por som, através de feedback, auxiliando-a na memorização e ordenação do alfabeto, reconhecendo-a de uma forma lúdica.

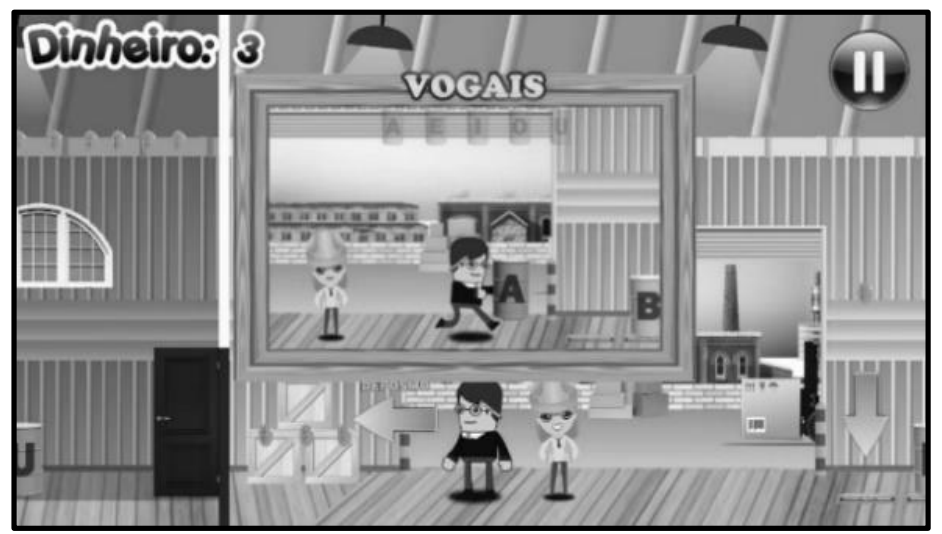

Figura 6: Tela da fase 1 - Feedback da tutora sobre a atividade.

Ao término da primeira fase, o jogador é direcionado ao cenário de escolha de fases, onde a fase 2 estará desbloqueada. Este processo ocorrerá todas as vezes em que uma fase for cumprida, desbloqueando sempre a fase seguinte.

A fase 2, apresentada na Figura 7, é similar a fase 1, ambientada na mesma fábrica e com objetivos semelhantes. O jogador deverá completar o alfabeto com as consoantes. Os feedbacks encontrados aqui também são similares à fase anterior, com explicação em áudio e em vídeo. 


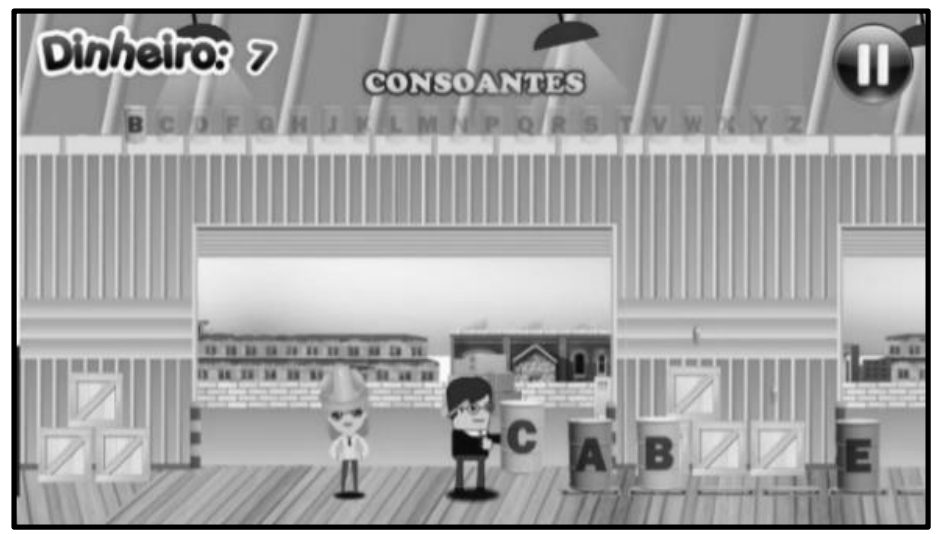

Figura 7: Tela da fase 2 - Ordenação de consoantes.

As pedagogas destacaram que através desta atividade, assim como na anterior, é possível que o professor diagnostique crianças que ainda não conhecem as letras do alfabeto e/ou sua sequência, possibilitando assim, direcionar suas atividades de uma forma mais eficiente. Esta atividade é uma forma de aprendizado àqueles que ainda estão em processo de alfabetização, incentivando-os a conhecer as consoantes, trabalhando sua ordem. Além disso, auxilia a criança a identificar consoantes por traço e por som, através de feedback, auxiliando-a na memorização e ordenação do alfabeto, reconhecendo-o de uma forma lúdica.

A fase 3, apresentada na Figura 8, tem como tema central o circo. O objetivo deste cenário é colocar as caixas com vogais, em ordem, sobre o trenzinho. Ao colocar as caixas nos lugares corretos, a "Professora Angélica" falará o nome de cada vogal e, ao término da fase, ocorrerão feedbacks da mesma maneira que nas fases anteriores.

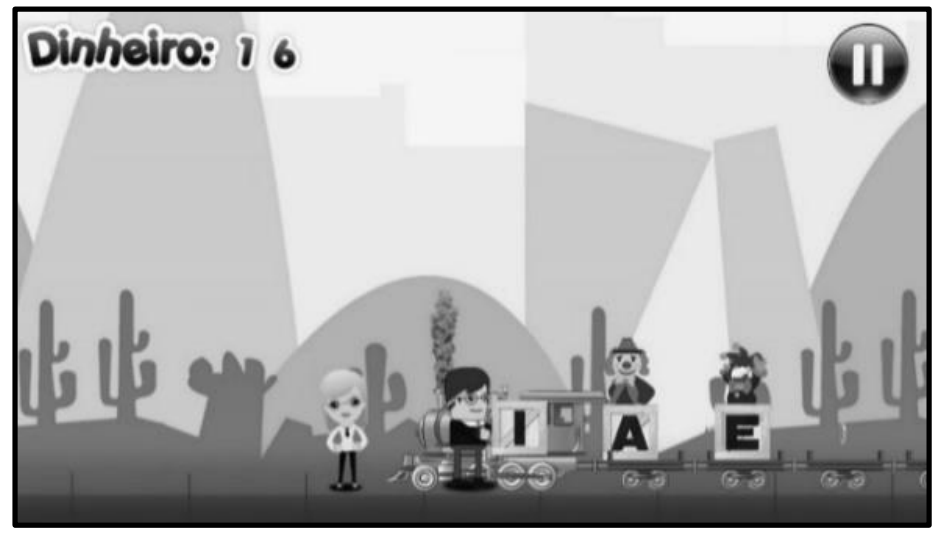

Figura 8: Tela da fase 3 - Ordenação de vogais.

Esta atividade tem como objetivo proporcionar uma aprendizagem lúdica, favorecendo a identificação, memorização e ordenação das vogais, que são passos importantes no aprendizado da leitura e escrita. Além disso, as pedagogas afirmam que a criança tem a oportunidade de aprender, nesta atividade por associação, o nome das vogais através do traço e de áudio por meio dos feedbacks.

A fase 4, apresentada na Figura 9, acontece em meio às montanhas, onde o jogador deverá coletar o maior número de vogais possíveis antes que o tempo acabe. Ao iniciar a fase, a "Professora Angélica" dará instruções ao jogador sobre a atividade, iniciando assim a contagem regressiva e o início do jogo. Cada letra correta coletada dará 1 ponto e cada letra incorreta subtrairá 1 ponto. Ao término da fase, a professora dará feedbacks e dirá a quantidade de pontos feita pelo jogador. 


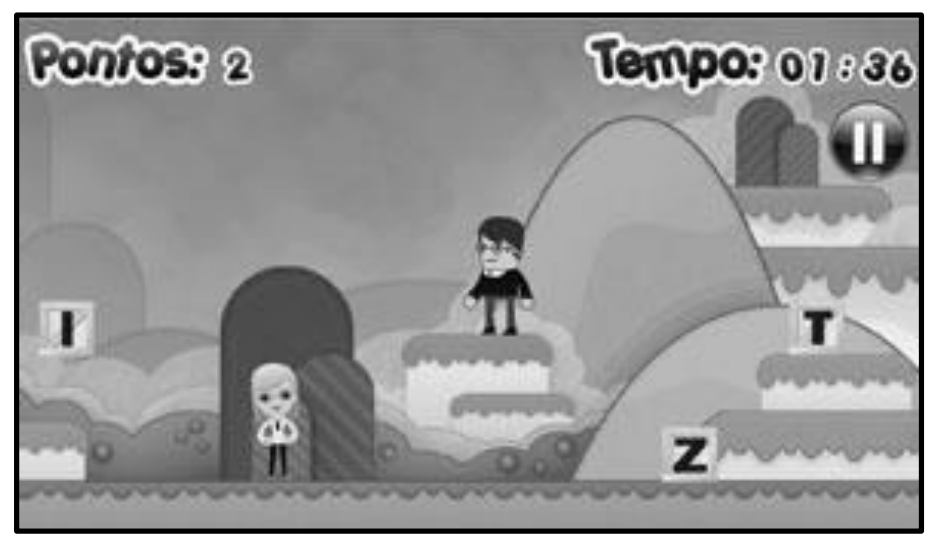

Figura 9: Tela da fase 4 - Coleta de vogais.

Esta atividade auxilia a criança no processo de memorização e distinção de traços de vogais e consoantes, aumentando sua habilidade de identificação e sua atenção. A atividade em questão proporciona, conforme observa uma das pedagogas, uma interação mais completa na forma de distinção entre vogais e consoantes, trazendo muitos benefícios e apurando ainda mais os conhecimentos adquiridos.

A fase 5, apresentada na Figura 10, é composta por quatro atividades. Durante o jogo, o jogador encontrará quatro personagens que lhe dirão como fazer cada atividade, sendo a primeira acompanhada pelo "Sebastião", um fazendeiro simpático que está ordenhando a vaca "Mimosa". O fazendeiro explicará os passos a serem dados pelo jogador para que o mesmo possa completar a palavra "leite", localizada em cima do caminhão do "Senhor Moacir", utilizando os latões com as vogais. Ao completar corretamente a palavra, o jogador receberá feedbacks em áudio e em vídeo.

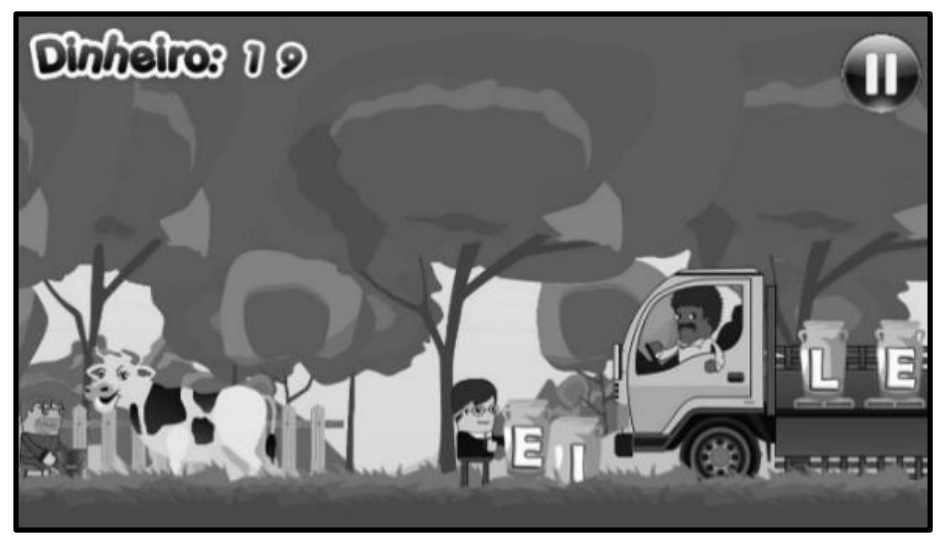

Figura 10: Tela da fase 5 - Escrita da palavra "Leite".

À frente, o jogador encontrará um grande palco contendo um músico e uma mocinha, a "Belinha", apresentados na Figura 11. Ao aproximar-se da personagem, o jogador receberá os feedbacks de como completar a atividade, onde o objetivo será completar a palavra "Música" colocando as caixas com vogais nas lacunas corretas sobre o palco. Completando a palavra com sucesso, a mocinha dará os feedbacks finais, surgindo na tela a palavra "Parabéns" e o nome do jogador. 


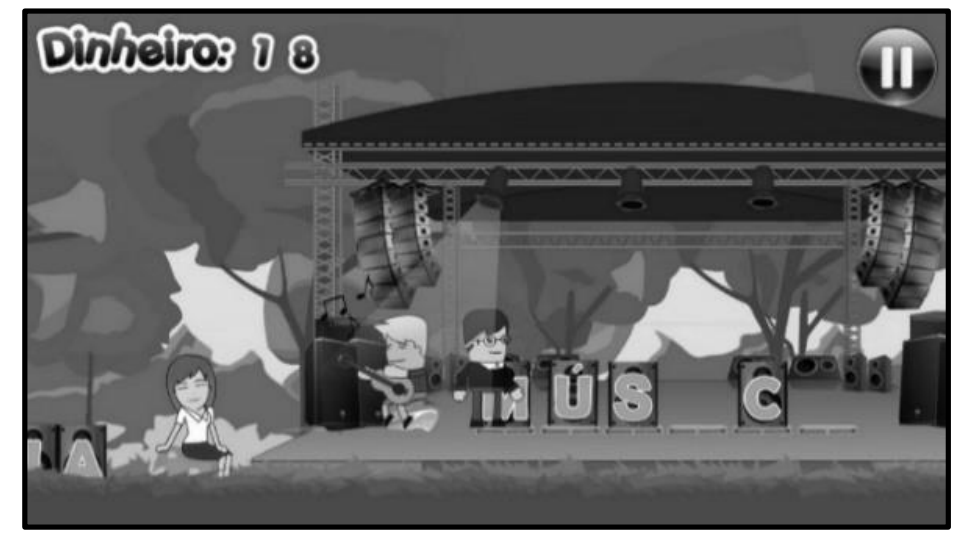

Figura 11: Tela da fase 5 - Escrita da palavra "Música".

Próximo a este local, o jogador encontrará a feira do "Seu Nenê", apresentado na Figura 12. Neste momento, o jogador receberá feedbacks em áudio e vídeo sobre como completar a palavra "Feira" com as caixas de frutas. A cada letra completada corretamente, o português dará feedbacks, assim como ao completar a palavra.

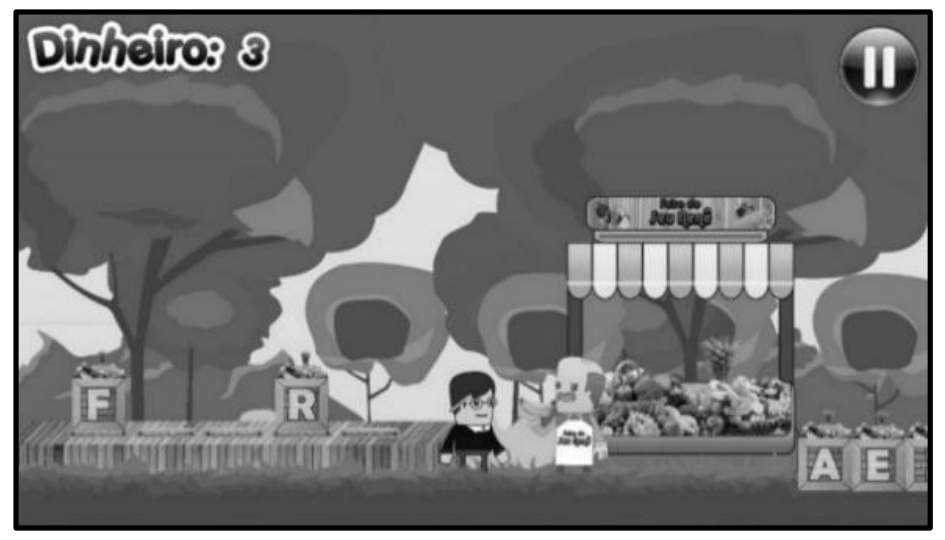

Figura 12: Tela da fase 5 - Escrita da palavra "Feira".

Na última atividade, o jogador chegará ao mar e encontrará o "Pirata" e seu papagaio tagarela, apresentados na Figura 13. O jogador, ao aproximar-se do pirata, receberá feedbacks em áudio e vídeo, os quais explicarão ao mesmo como completar a palavra "Tesouro" utilizando os baús com as vogais. Cada letra completada com sucesso dará um feedback e, ao terminar as atividades, o jogador receberá o feedback final da "Professora Angélica", assim como a palavra "Parabéns" e o nome do jogador fixados na tela.

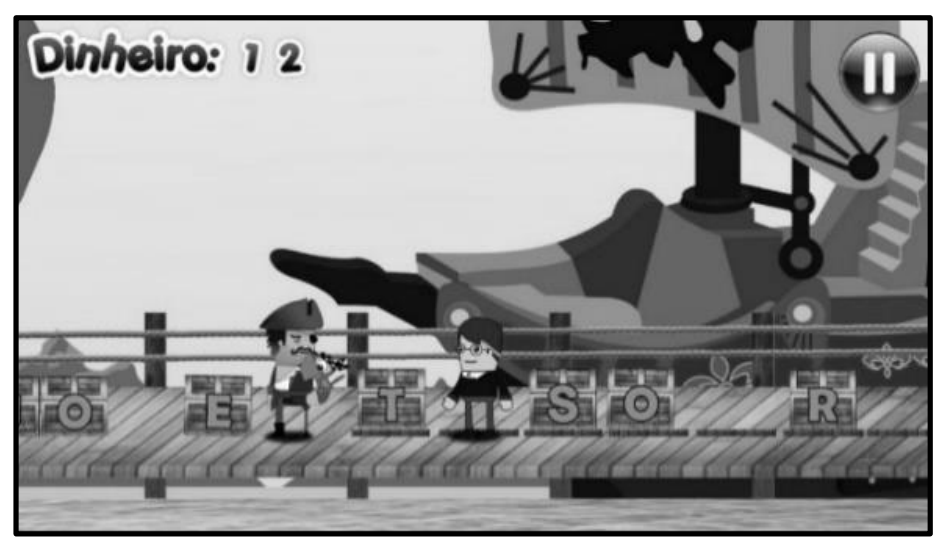

Figura 13: Tela da fase 5 - Escrita da palavra "Tesouro". 
Segundo as pedagogas, estas atividades proporcionam o desenvolvimento das habilidades de leitura, reconhecimento de vogais e consoantes, além de ampliar o vocabulário da criança. Assim como as atividades anteriores, esta atividade enriquece o aprendizado pela utilização de feedbacks, tanto em áudio quanto em imagem, ajudando a diferenciar os fonemas e grafemas ao completar cada palavra com as vogais que nelas faltam.

A fase 6, apresentada na Figura 14, é ambientada no espaço. Esta fase é uma roupagem do saudoso jogo Space Invaders. Existem diversas naves alienígenas lançando asteroides contendo vogais e consoantes, onde o objetivo é coletar cinco vogais de cada, evitando a todo custo ser atingido pelos asteroides das consoantes. No início da fase, a agora "Astronauta Angélica", explicará o que deverá ser feito pelo jogador e, ao término, o mesmo receberá feedbacks positivos e terá seu nome fixado na tela central.

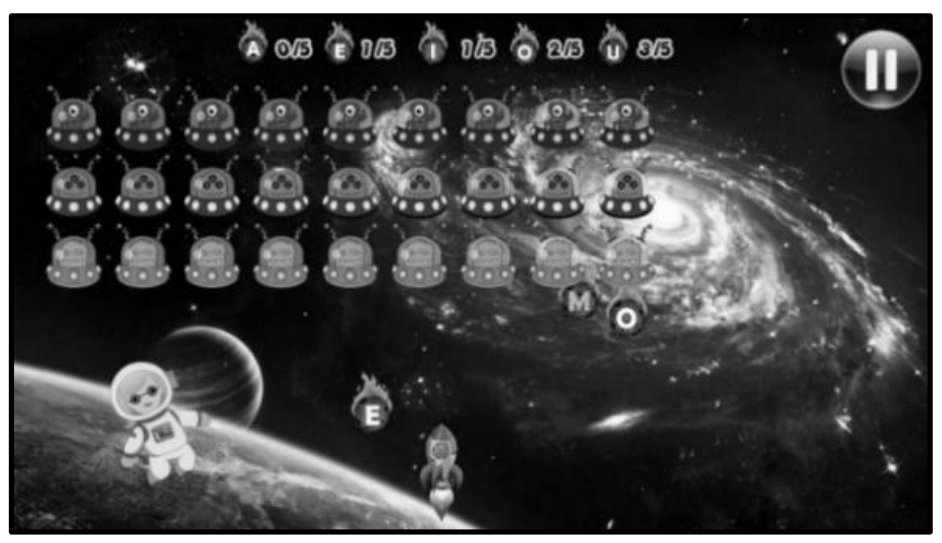

Figura 14: Tela da fase 6 - Coleta de vogais.

Esta atividade, conforme afirmação de uma das pedagogas, auxilia a criança no processo de memorização e distinção de traços de vogais e consoantes, aumentando a habilidade de identificação e sua atenção. A atividade em questão proporciona, de uma forma lúdica, uma interação ainda mais completa na forma de distinção entre vogais e consoantes, trazendo muitos benefícios e apurando seus conhecimentos adquiridos.

A fase 7, exibida na Figura 15, é ambientada em uma bela cidade. Aproximando-se da "Professora Angélica", a mesma explica os objetivos da atividade e como fazê-la. O jogador deve escrever as palavras referentes às imagens utilizando as caixas com as sílabas. Existem diversas sílabas nas caixas e estas estão misturadas entre si, o jogador deverá observar o desenho e colocar as sílabas corretas nas lacunas indicadas, recebendo feedbacks.

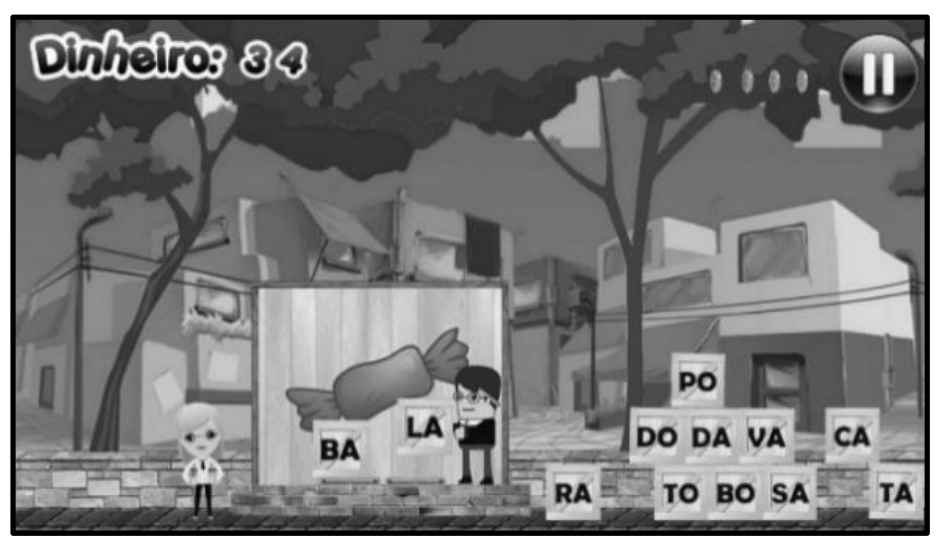

Figura 15: Tela da fase 7 - Escrita da palavra "Bala" com as sílabas. 
As pedagogas explicaram que esta atividade tem como objetivo apresentar às crianças as sílabas de uma forma lúdica, demonstrando a necessidade do uso das letras para a formação de sílabas e que desta junção podem formar também palavras. Além destes conceitos, a atividade aborda outros como a separação silábica e a constituição das palavras e sílabas.

A fase seguinte é o cenário da segunda mini fase, descrita na Figura 16. Esta mini fase é necessária para que o jogador se ambiente aos novos controles do jogo. Desta vez, o jogador deverá utilizar o mouse para puxar o personagem e soltá-lo, arremessando-o em direção a um alvo.

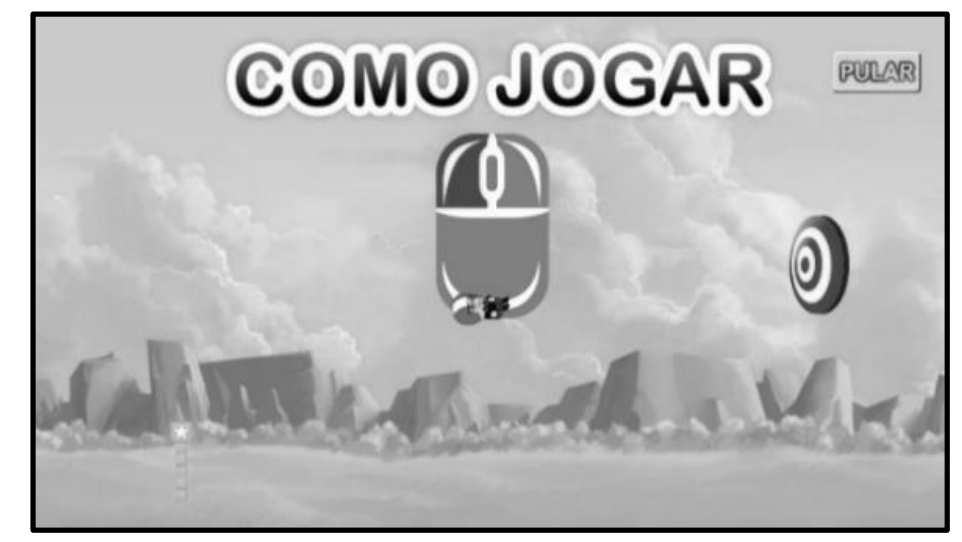

Figura 16: Tela da mini fase "Como Jogar" - Como arremessar o personagem.

A oitava e última fase, apresentada na Figura 17, é ambientada em uma casa assombrada, na qual existem três imagens distintas e o nome de uma delas fixo na tela. O jogador deve lê-la, clicar no personagem, arrastar o mouse, mirar a imagem correta e atirar. Ao acertar a imagem correta, a imagem desaparecerá, a "Bruxinha Angélica" dirá o nome da imagem e o personagem retornará ao ponto inicial para ser lançado novamente. Ao todo, são nove imagens diferentes a serem atingidas pelo jogador que, ao atingi-las, receberá feedbacks, parabenizando-o.

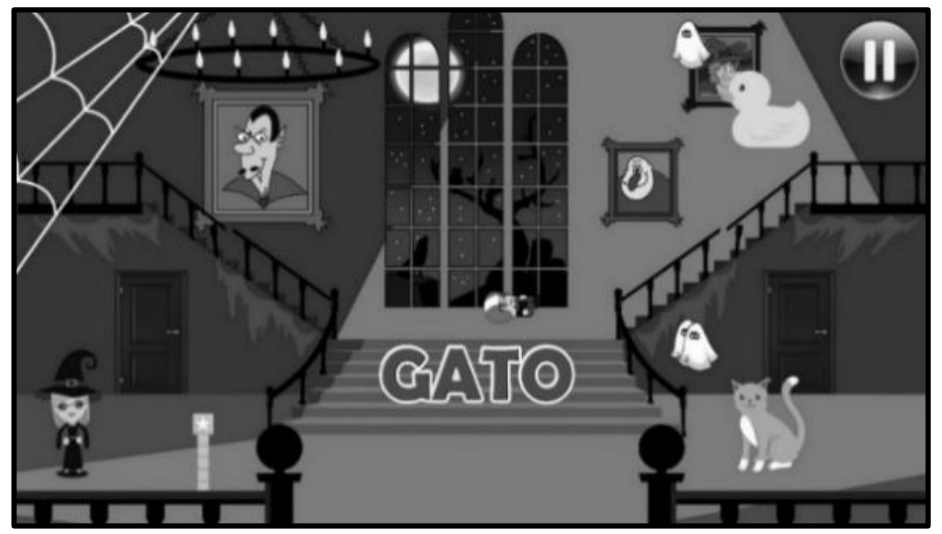

Figura 17: Tela da fase 8 - Arremesso do personagem na imagem "Gato".

Esta atividade, segundo uma das pedagogas, oferece às crianças a possibilidade de desenvolver ainda mais sua percepção ao som das palavras. Pela leitura da palavra, a criança constrói sua relação com o objeto, percebendo seu som, desenvolvendo sua memória, sua atenção e melhorando sua oralidade.

Ao terminar a fase 8, o jogador é enviado ao cenário final, apresentado na Figura 18. Este cenário marca o fim do jogo, onde há um feedback parabenizando-o pelo término de todas as atividades e tem seu nome fixado na tela. Ao final deste cenário, o jogador é enviado à tela inicial do jogo, onde o jogador pode refazer todas as fases na ordem que bem entender. 


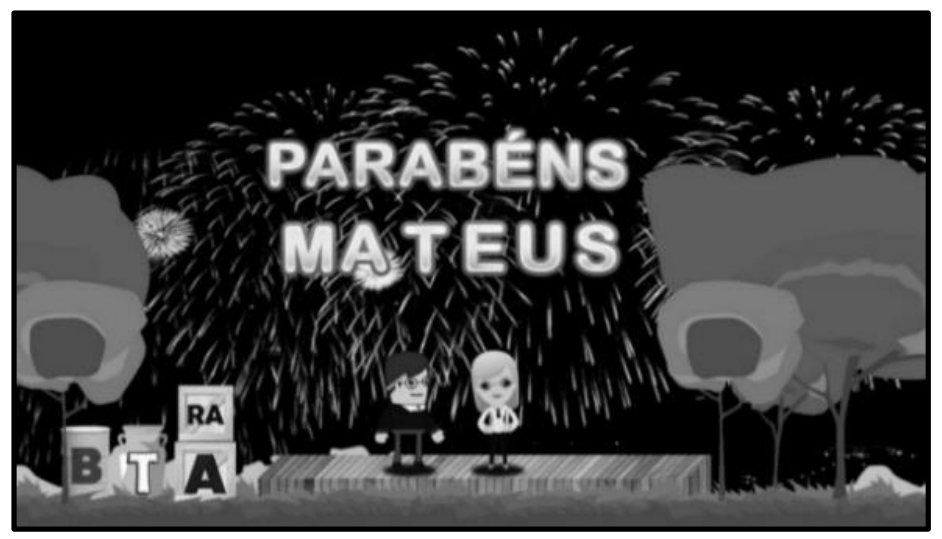

Figura 18: Tela de encerramento do Serious Game.

Todas as atividades contidas no jogo podem levar as crianças a momentos de interação e divertimento. Ao jogar, a criança tem um contato diferenciado com as atividades, facilitando a compreensão da natureza alfabética, estimulando o conhecimento das vogais e consoantes, a memorização e identificação das sílabas.

\section{Protocolo de Avaliação do Serious Game Joy e as Letrinhas}

Nesta seção, serão apresentados os procedimentos utilizados para avaliar o Serious Game como ferramenta de auxílio no processo de ensino/aprendizagem da alfabetização de crianças em início escolar e avaliar o mesmo quanto a sua usabilidade técnica e pedagógica por meio de conceitos dados por especialistas da área.

\subsection{Pesquisa qualitativa}

Foi realizada uma pesquisa qualitativa com o objetivo de:

- Avaliar a usabilidade e interação entre usuário e Serious Game, absorvendo feedbacks de profissionais da área, assim como informações sobre a aprendizagem e satisfação no uso do software.

- Avaliar a aplicabilidade do Serious Game como ferramenta de auxílio na aprendizagem, agregando feedbacks de profissionais da área.

- Avaliar a aquisição de conhecimentos específicos, a coleta de informações sobre a aprendizagem e a construção de conhecimentos individuais e coletivos.

O tipo de amostragem utilizada na coleta da pesquisa é caracterizada como nãoprobabilística, assim, mais especificamente, intitulada de amostra intencional. Esta amostra é dotada de indivíduos selecionados propositalmente pelo entrevistador, o qual julga os mesmos como detentores de características típicas ou representativas da população (Oliveira, 2013).

Com base neste contexto, foram escolhidas para a coleta de dados da pesquisa, três professoras que lecionam diretamente para crianças do Artesanato - Centro de Desenvolvimento Social de Mococa, com o intuito de conhecer, por meio de método prospectivo, opiniões sobre a usabilidade técnica e pedagógica do Serious Game. Desta forma, a avaliação poderá ser capaz de auxiliar na descoberta de possíveis adversidades, assessorar aperfeiçoamentos ou ajustes dos processos de interação entre usuário e Serious Game e, da perspectiva pedagógica, culminar em um Serious Game educativo de qualidade realmente propenso a ser utilizado como uma ferramenta no auxílio da alfabetização de crianças.

A coleta de dados foi efetuada por intermédio de um questionário constituído por vinte e nove questões, divididas em três seções. A primeira, chamada de "Critérios técnicos", é 
composta por onze questões referentes à avaliação da usabilidade técnica. A segunda, denominada de "Critérios pedagógicos", visa avaliar a usabilidade pedagógica do Serious Game. Por fim, a terceira seção é chamada de "Critérios de aquisição da leitura e escrita", a qual visa avaliar os critérios específicos pedagógicos. Estas questões foram baseadas nos trabalhos de Atayde, Teixeira e Pádua (2003), Coomans e Lacerda (2015) e Silva, França e Silva (2011).

Para cada um dos critérios das três seções mencionadas, os profissionais da educação atribuíram uma pontuação com base em uma escala Likert de cinco pontos. Segundo Cunha (2007), esta escala é constituída de certos itens onde o sujeito avaliador manifesta o seu grau de concordância de nível mais baixo até o seu nível mais alto, sendo utilizados os seguintes itens: Péssimo, Ruim, Bom, Ótimo e Excelente.

Para a referida avaliação do Serious Game pelas pedagogas do Artesanato - Centro de Desenvolvimento Social de Mococa, foram seguidas as seguintes etapas:

I. Exposição da pesquisa, explicações sobre sua importância e convite ao Artesanato e às pedagogas para sua contribuição com este trabalho.

II. Aplicação do Termo de Consentimento Livre e Esclarecido a todos as professoras participantes da pesquisa.

III. Apresentação e exposição do Serious Game às profissionais da educação (pedagogas) convidadas para a pesquisa.

IV. Utilização e testes do Serious Game pelas pedagogas em uma seção de quarenta a cinquenta minutos.

V. Aplicação do questionário às profissionais da educação.

VI. Exposição dos resultados obtidos.

\subsection{Pesquisa quantitativa}

Visando ao objetivo de avaliar a potencialidade do Serious Game "Joy e as Letrinhas" como ferramenta de auxílio no processo de ensino/aprendizagem da alfabetização para crianças em início escolar, a pesquisa em questão pretende apoiar as seguintes afirmações:

- "A pontuação média de cada habilidade trabalhada com as crianças antes da utilização do Serious Game "Joy e as Letrinhas" é inferior à adquirida posteriormente ao uso do mesmo".

- "A pontuação média das habilidades antes da utilização do Serious Game "Joy e as Letrinhas" é inferior à pontuação adquirida posteriormente ao uso do mesmo".

- Baseando-se nas afirmações 1 e 2, foram criadas as hipóteses a seguir.

- Para a afirmação de número 1 , temos:

- $\mathrm{H}_{0}$ : A pontuação média de cada habilidade trabalhada com as crianças antes da utilização do Serious Game "Joy e as Letrinhas" é igual ou superior a adquirida posteriormente ao uso do mesmo.

- $\mathrm{H}_{\mathrm{a}}$ : A pontuação média de cada habilidade trabalhada com as crianças antes da utilização do Serious Game "Joy e as Letrinhas" é inferior a adquirida posteriormente ao uso do mesmo.

- Para a afirmação de número 2, temos:

- $\mathrm{H}_{0}$ : A pontuação média das crianças antes da utilização do Serious Game Joy e as Letrinhas é igual ou superior à adquirida posteriormente ao uso do mesmo.

- $\mathrm{H}_{\mathrm{a}}$ : A pontuação média das crianças antes da utilização do Serious Game "Joy e as Letrinhas" é inferior à adquirida posteriormente ao uso do mesmo.

A hipótese $\mathrm{H}_{0}$ simboliza uma ideia contrária ao que se deseja averiguar. É esperado como resultado desta pesquisa a rejeição da hipótese nula $\mathrm{H}_{0}$. 
O tipo de amostragem empregada nesta pesquisa é qualificada como não-probabilística, mais especificamente denominada de amostragem por conveniência. Nesta amostragem são selecionados elementos supostamente semelhantes à população a qual se quer estudar (Marotti et al., 2008).

Fundamentado no exposto supracitado, para concretizar a avaliação do Serious Game em alunos em início do processo de alfabetização, foi escolhido o Artesanato - Centro de Desenvolvimento Social de Mococa, localizado na cidade de Mococa, interior de São Paulo. Os dados necessários foram coletados por meio de um questionário feito com alunos em início do processo de alfabetização. A composição do referido questionário baseia-se nos trabalhos de Atayde, Teixeira e Pádua (2003), Coomans e Lacerda (2015) e Silva, França e Silva (2011), e adaptado, conforme o propósito da pesquisa, com o auxílio de uma profissional com formação em pedagogia.

O questionário foi aplicado por uma pedagoga da Instituição, o qual dispõe de dezesseis questões divididas em duas seções, "Dados do aluno" e "Aspectos relacionados aos conteúdos trabalhados nas atividades". A primeira seção possui três questões gerais referentes aos dados do aluno. A segunda seção contém treze questões relacionadas às habilidades trabalhadas com as crianças em processo de alfabetização antes e após a realização das atividades no Serious Game "Joy e as Letrinhas".

A segunda seção do questionário dispõe, para cada habilidade, uma escala Likert de três pontos atribuída pela pedagoga com a seguinte representação: (1) Consegue Plenamente, (2) Consegue Parcialmente e (3) Não Consegue. A escala Likert é uma escala psicométrica intervalar $(1,2,3 \ldots)$ que utiliza-se de números para classificar objetos ou eventos. A escala em questão foi adotada pelo fato de possibilitar a utilização dos dados obtidos à submissão de cálculos complexos, como média, desvio padrão, teste t e entre outros (Larson \& Farber, 2010).

Foram seguidas as seguintes etapas para a avaliação do Serious Game "Joy e as Letrinhas" com as crianças em processo de alfabetização:

I. Exposição da proposta de pesquisa, parecer sobre a importância da mesma e o convite do pesquisador à instituição para a colaboração com o trabalho.

II. Aplicação do Termo de Consentimento Livre e Esclarecido a todos os alunos participantes da pesquisa.

III. Exposição e treinamento da pedagoga que trabalhará com as crianças com o Serious Game.

IV. Aplicação do questionário às crianças por parte da pedagoga, de modo a traçar seus perfis e quantificar seus conhecimentos prévios sobre o conteúdo tratado no Serious Game.

V. Utilização do Serious Game "Joy e as Letrinhas" com as crianças em processo de alfabetização do Artesanato - Centro de Desenvolvimento Social de Mococa em encontros semanais, com duração de uma hora e meia entre os períodos de 02 de fevereiro de 2016 à 08 de março de 2016.

VI. Nova aplicação do questionário às crianças por parte da pedagoga, de modo a quantificar seus conhecimentos sobre o conteúdo tratado no Serious Game após o período de utilização.

VII. Comparação e análise dos resultados obtidos pelos questionários anterior e posterior à utilização do Serious Game.

A comparação entre as médias anteriores e posteriores ao uso do Serious Game foi feita baseando-se no teste $t$, onde os dados obtidos foram caracterizados como amostras dependentes, onde cada criança traça dois valores, sendo os valores obtidos antes e depois do uso do Serious Game, consentindo sua comparação média entre as habilidades (Larson \& Farber, 2010). 
Foi estimado em 5\% o nível de significância. Este valor foi determinado utilizando como base a literatura de Larson e Farber (2010), sobressaltando que este parâmetro é habitualmente utilizado em trabalhos acadêmicos que envolvam testes estatísticos. Foi utilizada, além da estatística inferencial, teste $t$, a estatística descritiva de forma a organizar, resumir e representar os dados alcançados.

\section{Análise dos Resultados}

\subsection{Resultado da pesquisa quantitativa}

Participaram desta pesquisa onze alunos (A1, A2, ..., A11) escolhidos pelas pedagogas avaliadoras do Artesanato - Centro de Desenvolvimento Social de Mococa. Estes alunos têm entre seis e oito anos de idade, sendo cinco do sexo masculino e seis do sexo feminino, matriculados em escolas regulares e cursando entre o primeiro e o terceiro ano do ensino fundamental.

O gráfico, Figura 19, demostra a pontuação média das treze habilidades encontradas no questionário, com o objetivo de quantificar o conhecimento das amostras antes e depois da utilização do Serious Game. O teste de diferença das médias foi significativo ao nível de 5\%.

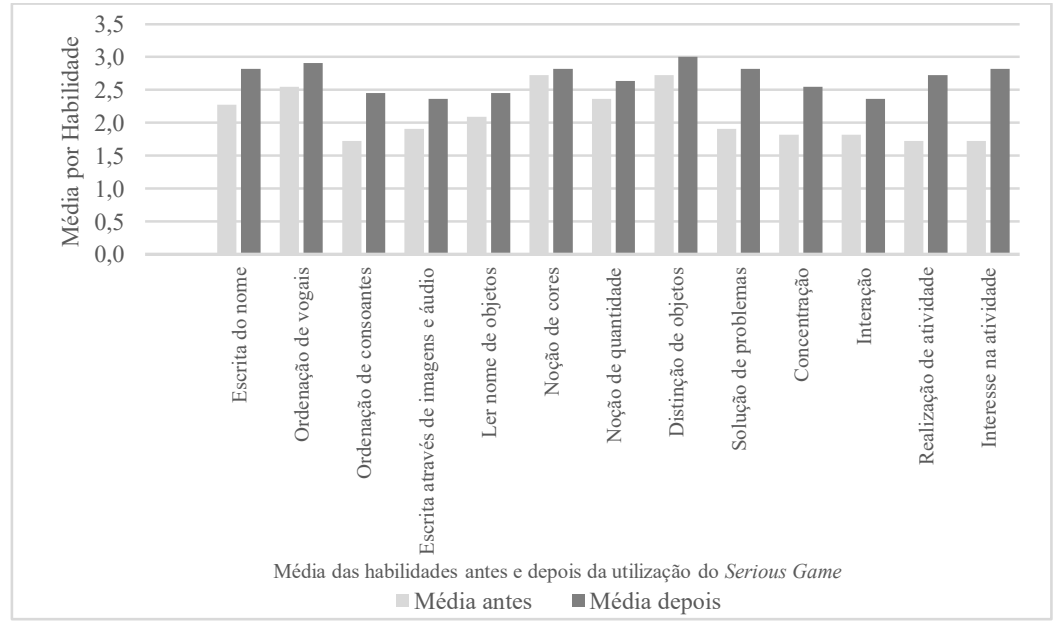

Figura 19: Média antes e depois das habilidades.

Para completar as informações do gráfico supracitado, o resultado do teste $\mathrm{t}$ por habilidade é apresentado na Tabela 1. É possível constatar, através desta tabela, que as médias após o uso do Serious Game, em todas as habilidades, foram maiores do que as médias verificadas antes da aplicação do mesmo.

Tabela 1: Resultado do teste $t$ por habilidade.

\begin{tabular}{ccccc}
\hline Habilidades & \multicolumn{2}{c}{ Média } & \multirow{2}{*}{} & $\boldsymbol{\alpha}=\mathbf{0 , 0 5}$ \\
& Antes & Depois & & g.l = 10 \\
\hline Escrita do nome & 2,27 & 2,82 & $-3,464$ & \\
Ordenação de vogais & 2,45 & 2,82 & $-2,390$ & \\
Ordenação de consoantes & 1,73 & 2,45 & $-5,164$ & \\
Escrita através de imagens e áudio & 1,82 & 2,36 & $-3,464$ & \\
Ler nome de objetos & 2,09 & 2,45 & $-2,390$ &
\end{tabular}




$\begin{array}{ccccc}\text { Noção de Cores } & 2,73 & 2,82 & -1,000 & \mathbf{t}_{\mathbf{0}}=-1,812 \\ \text { Noção de quantidade } & 2,36 & 2,64 & -1,936 & \\ \text { Distinção de objetos } & 2,64 & 3,00 & -2,390 & \\ \text { Solução de problemas } & 1,91 & 2,82 & -4,303 & \\ \text { Concentração } & 1,82 & 2,55 & -3,068 & \\ \text { Interação } & 1,82 & 2,36 & -2,206 & \\ \text { Realização de atividade } & 1,73 & 2,73 & -7,416 & \\ \text { Interesse na atividade } & 1,73 & 2,82 & -5,164 & \end{array}$

Posteriormente a aplicação do teste $t$, para cada habilidade, a estatística t encontra-se na região de rejeição em quase todas as habilidades em nível de significância de $5 \%$, onde $\mathrm{t}_{0}=$ 1,812. A habilidade noção de cores não apresentou diferença estatística significativa, entretanto houve um aumento na média. Já as habilidades escritas do nome, ordenação de consoantes, escrita através de imagens e áudio, solução de problemas, concentração, realização de atividade e interesse na atividade apresentaram uma diferença significativa de $1 \%(\alpha=0,01)$, onde $t_{0}=$ 2,764 .

Portanto, baseando-se nos resultados obtidos, verifica-se que há evidências suficientes para rejeitar a hipótese $\mathrm{H}_{0}$ referente à afirmação 1 apresentada na seção 4.2. Ao se aplicar o teste t, foi verificado estatisticamente que existem evidências suficientes para apoiar a afirmação: "a pontuação média de cada habilidade trabalhada com as crianças antes da utilização do Serious Game "Joy e as Letrinhas" é inferior à adquirida posteriormente ao uso do mesmo".

Foi aplicado o teste $\mathrm{t}$ para a pontuação média geral das habilidades antes e após o uso do Serious Game para verificar se esta pontuação média será menor que a alcançada posteriormente ao uso do mesmo. Com o resultado obtido, pode-se afirmar estatisticamente que existem evidências suficientes para se apoiar esta afirmação em nível de significância de $1 \%(\alpha=0,01)$, para $\mathrm{t}_{0}=-2,681$, onde o valor da estatística $\mathrm{t}$ foi de $-6,029$.

Ao analisar a Figura 20, pode-se perceber que a pontuação média de cada criança, assim como a média geral das mesmas, depois da utilização do Serious Game, são maiores do que as mensuradas antes da sua utilização.

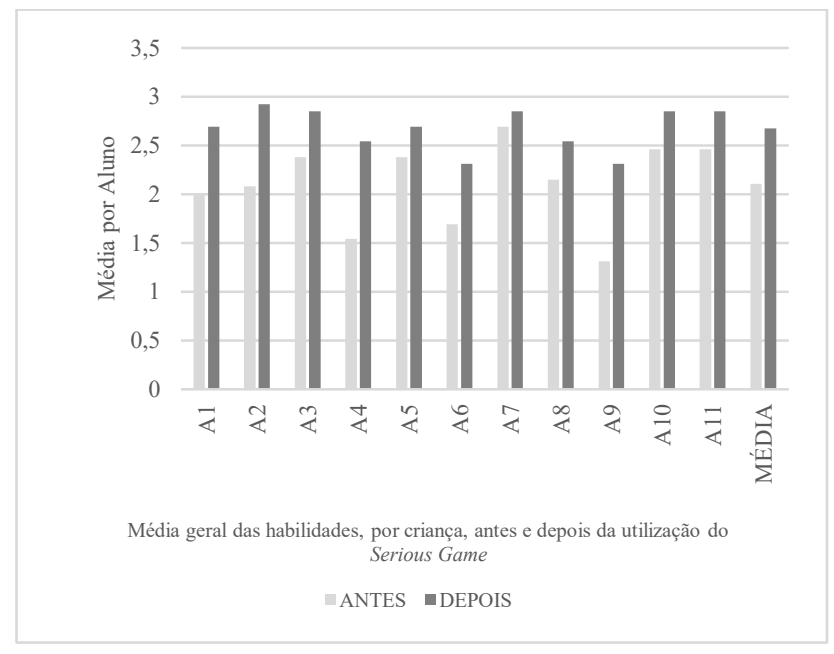

Figura 20: Média, por criança, das habilidades antes e depois do uso do Serious Game.

Após a realização do teste $t$ em cada uma das crianças, o valor da estatística t para dez das onze crianças participantes da pesquisa encontra-se na região de rejeição para nível de significância de $5 \%$, para g.l $=12$ e $t_{0}=-1,782$. Vale ressaltar que uma única criança, $A 7$, não possui uma diferença estatisticamente significativa para 5\%, entretanto, é possível observar que 
houve um aumento em suas médias e a diferença é estatisticamente significativa ao nível de $10 \%(\alpha=0,10)$, onde $t_{0}=-1,356$.

Tabela 2: Resultados das médias e teste t por aluno.

\begin{tabular}{|c|c|c|c|c|c|c|c|c|c|c|c|c|}
\hline Aluno & A1 & A2 & A3 & A4 & A5 & A6 & A7 & A8 & A9 & A10 & A11 & Média Geral \\
\hline Média Antes & 2,00 & 2,08 & 2,38 & 1,54 & 2,38 & 1,69 & 2,69 & 2,15 & 1,31 & 2,46 & 2,46 & 2,119 \\
\hline Média Depois & 2,69 & 2,92 & 2,85 & 2,54 & 2,69 & 2,31 & 2,85 & 2,54 & 2,31 & 2,85 & 2,85 & 2,665 \\
\hline Estatística t & $-3,323$ & $-8,124$ & $-2,521$ & $-5,099$ & $-2,309$ & $-4,382$ & $-1,477$ & $-2,132$ & $-5,099$ & $-2,739$ & $-2,739$ & $-6,029$ \\
\hline
\end{tabular}

Com os resultados obtidos supracitados, pode-se inferir, após a aplicação do teste $t$, que há evidências suficientes para se rejeitar a hipótese nula $\mathrm{H}_{0}$ referente à afirmação 2 apresentada na seção 4.2. Quando aplicado o teste $t$, foi verificado estatisticamente que existem evidências suficientes para apoiar a afirmação "a pontuação média das habilidades antes da utilização do Serious Game "Joy e as Letrinhas" é inferior à pontuação adquirida posteriormente ao uso do mesmo", no nível de significância de 5\%.

\subsection{Resultado da pesquisa qualitativa}

O Serious Game foi avaliado por três professoras (P1, P2 e P3) formadas em pedagogia e que trabalham diretamente com as crianças no Artesanato - Centro de Desenvolvimento Social de Mococa, há 3 e 4 anos respectivamente e, a última, 3 meses. A média de idade destas professoras é de 27 anos, onde a professora $\mathrm{P} 1$ possui 26 anos, a $\mathrm{P} 2$ possui 25 anos e a $\mathrm{P} 3$ possui 30 anos. O Serious Game foi avaliado pelas profissionais em uma seção de quarenta a cinquenta minutos cada uma, separadamente.

A Tabela 3 apresenta as médias das notas, referentes à avaliação da usabilidade técnica e pedagógica, dadas pelas pedagogas posteriormente à avaliação do Serious Games.

Tabela 3: Notas das seções do questionário.

\begin{tabular}{lccc}
\hline \multicolumn{1}{c}{ DIMENSÃO } & P1 & P2 & P3 \\
\hline Critérios técnicos & 4,45 & 4,18 & 4,36 \\
Critérios pedagógicos & 4,4 & 4,5 & 4,6 \\
Aquisição de conhecimentos & 4,0 & 3,87 & 4,5 \\
\hline
\end{tabular}

Dentre os critérios técnicos, as pedagogas avaliadoras destacaram algumas funções práticas do Serious Game, como a facilidade de instalação do mesmo. O Serious Game pode ser exportado no Construct 2 com a tecnologia Node-Webkit, que nada mais é do que a fusão de duas tecnologias (Node e Webkit). Esta fusão de tecnologias possibilita o desenvolvimento de aplicações desktop robustas utilizando todo o poder que ambas oferecem, principalmente em HTML5, Cascading Style Sheets (CSS) e Javascript. Utilizando esta tecnologia, a instalação do Serious Game torna-se desnecessária, configurando assim um software portátil.

Segundo as avaliadoras, o feedback é um dos quesitos mais importantes no processo de ensino/aprendizagem. Conforme Cardoso (2011), existem dois tipos de feedbacks em relação à complexidade, podem ser complexos ou não-complexos. Mensagens complexas costumam ser muito longas, complicadas e às vezes ineficazes, colocando em risco o foco e clareza das informações, assim como a distração do aluno. Por outro lado, as mensagens não-complexas são mensagens mais curtas, claras e objetivas que facilitam o entendimento por parte deste aluno.

As avaliadoras constataram que os feedbacks subsidiados pelo Serious Game ajudam no entendimento das atividades, principalmente por utilizarem diferentes métodos, como em imagem, áudio e vídeo. Destacaram, principalmente, a colocação da "Professora Angélica" 
como tutora nas atividades. Esta constatação se tornou pertinente na utilização do Serious Game pelos alunos A6 e A9, os quais ainda não foram alfabetizado. Estes alunos, por terem dificuldade na leitura, utilizando como ponto primordial a utilização dos feedbacks de áudio, feitos pela "Professora Angélica" e pela demonstração em vídeo, tornaram a atividade menos propensa a dúvidas. Outro ponto positivo levantado pelas pedagogas foram os feedbacks positivos nos acertos das atividades. Ao colocar uma letra correta, o jogo emite um feedback sonoro, o nome da letra, e um visual, faíscas, por exemplo. As pedagogas explicaram que ao emitir o feedback positivo, além de encorajar e premiar o jogador, ajuda o mesmo na alfabetização, fazendo uma ligação audiovisual entre imagem e fonema, tornando o aprendizado ainda mais completo.

Os cenários utilizados no Serious Game tendem a seguir um tema específico, como observado pelas avaliadoras. Estes temas favorecem o interesse do aluno, não apenas pelo contexto, mas pela inserção de atividades ligadas à imaginação. Um exemplo disso são os cenários das fases vividas no espaço e na casa assombrada, onde pela imaginação e vivência do aluno no ambiente da atividade, colocou sua imaginação à prova. Os alunos A2, A5, A10 e A11, enquanto utilizavam o Serious Game nestas fases, falavam sobre astronautas, planetas, fantasmas, casas assombradas e etc, expondo seus sonhos e medos enquanto faziam as atividades.

Os critérios técnicos obtiveram uma pontuação satisfatória e a usabilidade tornou a manipulação do Serious Game agradável e de fácil manuseio. As avaliadoras destacaram a importância da facilidade de manuseio perante as dificuldades que os alunos poderiam encontrar na utilização do Serious Game. A utilização tornou-se viável mesmo para os alunos que possuem dificuldades no manuseio do mouse e/ou teclado, pois propiciam, além do auxílio na alfabetização, a melhoria da sua habilidade motora.

$\mathrm{Na}$ análise dos critérios pedagógicos, as pedagogas avaliadoras destacaram a importância e sua satisfação quanto ao grau de dificuldade dos conteúdos tratados no Serious Game. É de suma importância que haja níveis de complexidade entre as atividades para que o aluno possa avançar no seu desenvolvimento em leitura e escrita. O Serious Game aborda esta complexidade nas atividades, tanto em cenários de atividades únicas quanto em cenários que apresentam várias atividades, propondo desafios, fazendo com que o aluno precise buscar e descobrir formas para se chegar ao objetivo.

A motivação é um dos elementos chave para o sucesso da aprendizagem. As crianças, por si só, têm um interesse muito grande quando o assunto é tecnologia, mas prender a atenção dos mesmos não é uma tarefa simples. Nos dias que se seguiram nos testes com os alunos, as pedagogas avaliaram o grau de atenção que os mesmos deram às atividades do Serious Game. Os alunos A1, A2, A5, A8, A9 e A10 ficaram eufóricos ao descobrirem que, ao coletarem um número $\mathrm{x}$ de moedas, era possível adquirir personagens de diferentes estilos. Com esta motivação, os alunos quiseram jogar mesmo depois que os testes terminaram. As pedagogas acharam interessante a inserção de personagens de diferentes tipos no Serious Game, pois os mesmos chamam a atenção das crianças, motivando-as a continuar jogando.

As atividades apresentadas, segundo a pedagoga P1, favorecem o aprendizado das crianças de uma maneira bem significativa. Estas atividades provocam um interesse ainda maior por meio das descobertas feitas no Serious Game.

As pedagogas salientaram a importância dos critérios de aquisição de conhecimentos, destacando alguns pontos positivos do Serious Game. Um destes pontos foi a facilidade de identificação dos símbolos gráficos. A pedagoga P3 achou formidável a forma com a qual os símbolos foram dispostos, escritos em caixa alta, pois as crianças, por não estarem alfabetizadas por completo, têm dificuldades na leitura de letras minúsculas. As pedagogas P1 e P2 
comentaram sobre o uso das letras nos objetos, a utilização das mesmas e o contexto ao qual foram empregadas, facilitando sua identificação. Como exemplo, é possível citar a atividade onde o jogador deve escrever a palavra "leite", as letras estão inseridas em latões de leite e em volta existem vários elementos que levam o jogador a perceber o contexto e, assim, a palavra a qual deve completar.

Tratando-se de consciência fonológica, as pedagogas P1 e P2 disseram estar contentes quando a este quesito. As pedagogas ressaltaram a importância de atividades que explorem a consciência fonológica, as quais são existentes em quase todas as atividades do Serious Game.

Consciência fonológica, segundo Paulino (2009), é a compreensão, por parte da criança, de que o nome atribuído a cada letra do alfabeto, aproxima-se aos sons da fala que podem ser representados na escrita. Dominar o nome da letra e saber o som da mesma ajuda a compreender que o seu valor funcional nas palavras é pré-estabelecido.

Esta consciência é destacada nos feedbacks dados, principalmente, pela "Professora Angélica" ao colocar as letras em seus devidos lugares, onde é dito o nome destas letras, da mesma forma quando as palavras são completadas. Assim, com a repetição dos grafemas, fonemas e sílabas, as crianças podem aprender, assimilar e associar o nome de cada letra do alfabeto.

A pedagoga P3 achou interessante a forma como as atividades são feitas no Serious Game. Com a utilização de feedbacks e um contexto que aproxima as palavras da realidade da criança, as mesmas conseguiram formar as palavras nas atividades utilizando as letras que faltavam. Esta fala pode ser observada na execução das fases cinco e sete, as quais têm a necessidade de completar as palavras utilizando as vogais e as sílabas que estão faltando respectivamente.

As avaliadoras foram unânimes quanto à qualidade das atividades oferecidas. Foram destacadas, principalmente, as possibilidades que o Serious Game pode proporcionar, permitindo o auxílio na aprendizagem, promovendo a identificação dos símbolos gráficos, a consciência fonológica, as relações entre grafemas e fonemas e possibilidade de escrita de palavras.

\section{Considerações Finais}

Os jogos educacionais oferecem um universo de possibilidades, formas de educar e instruir as crianças. São convidativos, abrem as portas da imaginação, levam os pequeninos a um mundo encantado, onde aprender é a palavra mágica. As metodologias tradicionais, focadas no educador, quadro negro e giz cada vez mais dão lugar às inovações, às novas tecnologias e, porque não, uma nova cultura no ensino, centrada no aluno, no software e na combinação destes?

Utilizando-se desta afirmação, a presente pesquisa traz como proposta apresentar um Serious Game para auxílio no processo de ensino/aprendizagem da alfabetização de crianças em início escolar de forma a minimizar os problemas de aprendizagem. Batizado de "Joy e as Letrinhas", o Serious Game, baseado nos resultados obtidos, apresentou sinais de contribuição no processo de ensino/aprendizagem, colaborando com um aumento significativo das habilidades das crianças, onde os métodos tradicionais se mostraram ineficientes, confirmando, assim, as duas hipóteses elaboradas na seção 4.2. É possível afirmar que o Serious Game "Joy e as Letrinhas" alcançou os objetivos desejados e pode ser utilizado por crianças em início escolar no âmbito da alfabetização. 
Este Serious Game é de fácil aprendizagem, trazendo informações claras e feedbacks importantes que facilitam o entendimento quanto aos objetivos a serem alcançados. Além disso, aborda uma temática simples e divertida, permitindo uma maior interação entre a criança e o jogo, motivando-a na construção de conhecimentos individuais e coletivos, além de aprender de uma forma divertida e lúdica.

Assim, como trabalhos futuros é proposto:

- Integrar novas funções de jogabilidade ao jogo, como escolha de joystick ou teclado.

- Inserir novas atividades e maiores desafios.

- Integrar um banco de dados para colher informações referentes às atividades e aos passos do jogador no jogo.

- Explorar atividades voltadas a alunos com deficiências intelectuais.

- Adicionar funcionalidade de multijogador, atendendo a pedidos, incluindo uma personagem do sexo feminino selecionável.

- Desenvolver este jogo em uma engine mais completa, explorando a tecnologia 3D.

\section{Referências}

Araújo, A. P. Q. C. (2002). Avaliação e manejo da criança com dificuldade escolar e distúrbio de atenção. Jornal de Pediatria, 78(1), 104-110. VISUALIZAR ITEM. [GS Search].

Araújo, V., \& Rodrigues, S. H. (2007). Alfabetização na era digital: olhos e ouvidos imaginários, $A B E D$. Curitiba, $13^{\circ}$ Congresso Internacional de Educação a Distância. VISUALIZAR ITEM. [GS Search].

Atayde, A. P. R., Teixeira, A. B. M., \& Pádua, C. I. S. (2003). MAQSEI - uma Metodologia de Avaliação de Qualidade de Software Educacional Infantil. In Brazilian Symposium on Computers in Education - Simpósio Brasileiro de Informática na Educação, 1(1), 356-365. VISUALIZAR ITEM. [GS Search].

Barboza, A. T., \& Silveira, I. F. (2015). Brincando com as Letras: Um serious game para o ensino do Alfabeto. In Anais dos Workshops do Congresso Brasileiro de Informática na Educação 4(1), 377. VISUALIZAR ITEM. [GS Search].

Bartholomeu, D., Sisto, F. F., \& Rueda, F. M. J. (2006). Dificuldades de aprendizagem na escrita e características emocionais de crianças. Psicologia em Estudo, 11(1), 139-146. VISUALIZAR ITEM. [GS Search].

Cardoso, A. C. S. (2011). Feedback em contextos de ensino-aprendizagem on-line. Linguagens e Diálogos, 2(2), 17-34. VISUALIZAR ITEM. [GS Search].

Coomans, S., \& Lacerda, G. S. (2015). PETESE, a Pedagogical Ergonomic Tool for Educational Software Evaluation. Procedia Manufacturing, 3, 5881-5888. VISUALIZAR ITEM. [GS Search].

Coscarelli, C. V., Dallapicula, V. A., Mota, R. R., \& Gonçalves, L. D. (2008). Alfabetização na Internet: analisando a prática. In VII Brazilian Symposium on Computer Games and Digital Entertainment November, 146. VISUALIZAR ITEM. [GS Search].

Costa, T. K. L., Machado, S. L. \& Morais, R. M. (2014). Inteligência artificial e sua aplicação em serious games para saúde. Revista Eletrônica de Comunicação, Informação \& Inovação em Saúde, 8(4). VISUALIZAR ITEM. [GS Search].

Cruz, P., \& Monteiro, L. (2012). Anuário brasileiro da educação básica 2012. São Paulo: Moderna. VISUALIZAR ITEM. [GS Search]. 
Cunha, L. M. A. (2007). Modelos Rasch e Escalas de Likert e Thurstone na medição de atitudes. Dissertação de Mestrado em Probabilidades e Estatística, Faculdade de Ciências, Universidade de Lisboa, Lisboa, Portugal. VISUALIZAR ITEM. [GS Search].

Domingos, G. A. (2007). Dificuldades do processo de aprendizagem. Vila Velha, ESAB Escola Superior Aberta do Brasil. Vila Velha - ES, Brasil. VISUALIZAR ITEM. [GS Search].

Fleury, A., Nakano, D., \& Cordeiro, J. H. D. O. (2014). Mapeamento da indústria brasileira e global de jogos digitais. São Paulo: GEDIGames/USP. VISUALIZAR ITEM. [GS Search].

Gulo, C. A. S. J., Cunha, L. M., Neto, J. S., de Araujo, A. F., Machado, J., \& Dota, M. (2011). Utilizando GCompris na Escola. II Encontro nacional de informática e educação, 225-264. VISUALIZAR ITEM. [GS Search].

Karlini, D., \& Rigo, S. J. (2014). ABCLINGO: Integrando Jogos Sérios e Mineração de Dados Educacionais no Apoio ao Letramento. Proceedings of SBGames, 1149-1152. VISUALIZAR ITEM. [GS Search].

Klopfer, E., Osterweil, S., \& Salen, K. (2009). Moving learning games forward. Cambridge, MA: The Education Arcade. VISUALIZAR ITEM. [GS Search].

Larson, R., \& Farber, B. (2010). Estatística Aplicada. 4. ed. São Paulo: Pearson Prentice Hall. São Paulo - SP, Brasil. [GS Search].

Lazzarotto, E. F. S. (2010). Alfabetização e letramento. Três Cachoeiras, Universidade Federal do Rio Grande do Sul - UFRGS. VISUALIZAR ITEM. [GS Search].

Machado, L. S., Moraes, R. M., Nunes, F. L. S., \& Costa, R. M. E. M. (2011). Serious games baseados em realidade virtual para educação médica. Revista Brasileira de Educação Médica , 35(2), 254-262. VISUALIZAR ITEM. [GS Search].

Marotti, J., Galhardo, A. P. M., Furuyama, R. J., Pigozzo, M. N., Campos, T. N., \& Laganá, D. C. (2008). Amostragem em pesquisa clínica: tamanho da amostra. Revista de Odontologia da Universidade Cidade de São Paulo, 20(2), 186-194. VISUALIZAR ITEM. [GS Search].

Martin, D. T. (2005). Práticas de alfabetização nas séries iniciais do ensino fundamental: Uma análise das metodologias na perspectiva histórico-cultural. VISUALIZAR ITEM. [GS Search].

Ministério da Educação, INEP. (2015). Avaliação Nacional da Alfabetização 2014. VISUALIZAR ITEM. [GS Search].

Moreira, M. E. R., \& Rocha, E. A. G. M. (2013). Alfabetizar letrando: novos desafios no ensino da língua escrita. Revista Saberes Interdisciplinares. Belo Horizonte, 12 (12), 25. VISUALIZAR ITEM. [GS Search].

Nascimento, P. C. C. \& Cavalcante, L. M. (2012). Linguagem e infância: Concepções de alfabetização e letramento das professoras na educação infantil. Campina Grande: REALIZE Editora. VISUALIZAR ITEM. [GS Search].

Oliveira, L. R. (2013). Implementação de processos: o uso de técnicas de estimativas de projetos de software para estimar processos de negócio. Projetos e Dissertações em Sistemas de Informação e Gestão do Conhecimento, 1(1). VISUALIZAR ITEM. [GS Search].

Oliveira, T. M. V. (2001). Amostragem não probabilística: adequação de situações para uso e limitações de amostras por conveniência, julgamento e quotas. Administração on line, 2(3). VISUALIZAR ITEM. [GS Search]. 
Paulino, J. I. B (2009). Consciência fonológica - Implicações na aprendizagem da leitura. Dissertação de Mestrado, Faculdade de Psicologia e Ciências da Educação, Universidade de Coimbra. VISUALIZAR ITEM. [GS Search].

Pereira, C. C., Vitória, G. S., Santos, N. F., \& Machado, S. C. S. (2013). Alfabetização: métodos $e$ algumas reflexões. Caldas Novas, UNICALDAS - Faculdade de Caldas Novas. VISUALIZAR ITEM. [GS Search].

Petronilo, A. P. S. (2007). Dificuldade de aprendizagem na leitura e na escrita. Brasília, Universidade de Brasília - Centro de Ensino a Distância. Recuperado em 12 de janeiro, 2016, de VISUALIZAR ITEM. [GS Search].

Rivas, N. P. P., Silva, H. M. G., \& Conte, K, M. (2014). Didática do Ensino Superior. [Desenvolvimento e atualização de material didático]. Batatais: Claretiano. VISUALIZAR ITEM. [GS Search].

Rocha, R. L. D. (2015). Jogos digitais como estratégia de aprendizado: uma proposta de aplicação para o ensino da administração pública. Recuperado em 27 de fevereiro, 2016, de VISUALIZAR ITEM. [GS Search].

Savi, R., \& Ulbricht, V. R. (2008). Jogos digitais educacionais: benefícios e desafios. Revista Novas Tecnologias na Educação, 6(2), 10. VISUALIZAR ITEM. [GS Search].

Silva, A. C. B., de França, R. S., \& Silva, W. C. (2011). Uma proposição de critérios para avaliação de softwares educativos de Língua Portuguesa. In Brazilian Symposium on Computers in Education - Simpósio Brasileiro de Informática na Educação, 1(1). VISUALIZAR ITEM. [GS Search].

Silva, A. F. V., Couto, I. C., \& França, J. A. (2013). Percepção dos professores do ensino fundamental sobre as dificuldades de aprendizagem. VISUALIZAR ITEM. [GS Search].

Silva, L. A. O., \& Rodrigues, R. R. (2011). Letramento e alfabetização na educação infantil: concepções e práticas pedagógicas de educadoras do pré-escolar de Ouro Preto-MG. Oikos: Revista Brasileira de Economia Doméstica, 22(1), 25-45. VISUALIZAR ITEM. [GS Search].

Soares, M. (1998). O que é letramento e alfabetização. SOARES, M. Letramento: um tema em três gêneros. Belo Horizonte: Autêntica. VISUALIZAR ITEM. [GS Search].

Todos Pela Educação. (2013). São Paulo, Editora Moderna. VISUALIZAR ITEM. [GS Search].

Vanni, J. T. C. (2014). Serious Games e Gamificação: Aplicações no ensino e perspectivas para o futuro. São Paulo. Recuperado em 15 de janeiro, 2016, de VISUALIZAR ITEM. [GS Search]. 